\title{
Comparative genomic analysis of C4 photosynthetic pathway evolution in grasses Xiyin Wang ${ }^{* \dagger}$, Udo Gowik ${ }^{\ddagger}$, Haibao Tang ${ }^{*}$, John E Bowers ${ }^{*}$, Peter Westhoff ${ }^{\ddagger}$ and Andrew H Paterson*§
}

\begin{abstract}
Addresses: * Plant Genome Mapping Laboratory, University of Georgia, Athens, GA 30602, USA. ${ }^{\dagger}$ College of Sciences, Hebei Polytechnic University, Tangshan, Hebei 06300o, China. ${ }^{*}$ Institut fur Entwicklungs- und Molekularbiologie der Pflanzen, Heinrich-Heine-Universitat 1, Universitatsstrasse, D-40225 Dusseldorf, Germany. §Department of Plant Biology, University of Georgia, Athens, GA 30602, USA.
\end{abstract}

Correspondence: Andrew H Paterson. Email: paterson@uga.edu

Published: 23 June 2009

Genome Biology 2009, 10:R68 (doi:10.1 186/gb-2009-10-6-r68)

The electronic version of this article is the complete one and can be found online at http://genomebiology.com/2009/10/6/R68
Received: 18 March 2009

Revised: 27 May 2009

Accepted: 23 June 2009

(C) 2009 Wang et al.; licensee BioMed Central Ltd.

This is an open access article distributed under the terms of the Creative Commons Attribution License (http://creativecommons.org/licenses/by/2.0), which permits unrestricted use, distribution, and reproduction in any medium, provided the original work is properly cited.

\begin{abstract}
Background: Sorghum is the first C4 plant and the second grass with a full genome sequence available. This makes it possible to perform a whole-genome-level exploration of C4 pathway evolution by comparing key photosynthetic enzyme genes in sorghum, maize (C4) and rice (C3), and to investigate a long-standing hypothesis that a reservoir of duplicated genes is a prerequisite for the evolution of C4 photosynthesis from a C3 progenitor.

Results: We show that both whole-genome and individual gene duplication have contributed to the evolution of C4 photosynthesis. The C4 gene isoforms show differential duplicability, with some C4 genes being recruited from whole genome duplication duplicates by multiple modes of functional innovation. The sorghum and maize carbonic anhydrase genes display a novel mode of new gene formation, with recursive tandem duplication and gene fusion accompanied by adaptive evolution to produce $\mathrm{C} 4$ genes with one to three functional units. Other $\mathrm{C} 4$ enzymes in sorghum and maize also show evidence of adaptive evolution, though differing in level and mode. Intriguingly, a phosphoenolpyruvate carboxylase gene in the C3 plant rice has also been evolving rapidly and shows evidence of adaptive evolution, although lacking key mutations that are characteristic of C4 metabolism. We also found evidence that both gene redundancy and alternative splicing may have sheltered the evolution of new function.

Conclusions: Gene duplication followed by functional innovation is common to evolution of most but not all C4 genes. The apparently long time-lag between the availability of duplicates for recruitment into $\mathrm{C} 4$ and the appearance of $\mathrm{C} 4$ grasses, together with the heterogeneity of origins of $\mathrm{C} 4$ genes, suggests that there may have been a long transition process before the establishment of $\mathrm{C} 4$ photosynthesis.
\end{abstract}




\section{Background}

Many of the most productive crops in agriculture use the $\mathrm{C}_{4}$ photosynthetic pathway. Despite their multiple origins, they are all characterized by high rates of photosynthesis and efficient use of water and nitrogen. As a morphological and biochemical innovation [1], the $\mathrm{C}_{4}$ photosynthetic pathway is proposed to have been an adaptation to hot, dry environments or $\mathrm{CO}_{2}$ deficiency [2-5]. The $\mathrm{C}_{4}$ pathway independently appeared at least 50 times during angiosperm evolution $[6,7]$. Multiple origins of the $\mathrm{C}_{4}$ pathway within some angiosperm families $[8,9]$ imply that its evolution may not be complex, perhaps suggesting that there may have been genetic predeposition in some $\mathrm{C}_{3}$ plants to $\mathrm{C}_{4}$ evolution [6].

The high photosynthetic capacity of $\mathrm{C}_{4}$ plants is due to their unique mode of $\mathrm{CO}_{2}$ assimilation, featuring strict compartmentation of photosynthetic enzymes into two distinct cell types, mesophyll and bundle-sheath (illustrated in Figure 1 for the NADP-malic enzyme (NADP-ME) type of $\mathrm{C}_{4}$ pathway). First, $\mathrm{CO}_{2}$ assimilation is carried out in mesophyll cells. The primary carboxylating enzyme, phosphoenolpyruvate carboxylase (PEPC), together with carbonic anhydrase (CA), which is crucial to facilitating rapid equilibrium between $\mathrm{CO}_{2}$ and $\mathrm{HCO}_{3}^{-}$, is responsible for the hydration and fixation of $\mathrm{CO}_{2}$ to produce a $\mathrm{C}_{4}$ acid, oxaloacetate. In NADP-ME-type $\mathrm{C}_{4}$ species, oxaloacetate is then converted to another $\mathrm{C}_{4}$ acid, malate, catalyzed by malate dehydrogenase (MDH). Malate then diffuses into chloroplasts in the proximal bundle-sheath cells, where $\mathrm{CO}_{2}$ is released to yield pyruvate by the decarboxylating NADP-ME. The released $\mathrm{CO}_{2}$ concentrates around the secondary carboxylase, Rubisco, and is reassimilated by it through the Calvin cycle. Pyruvate is transferred back into mesophyll cells and catalyzed by pyruvate orthophosphate dikinase (PPDK) to regenerate the primary $\mathrm{CO}_{2}$ acceptor, phosphoenolpyruvate. Phosphorylation of a conserved serine residue close to the amino-terminal end of the PEPC polypeptide is essential to its activity by reducing sensitivity to the feedback inhibitor malate and a catalyst named PEPC kinase (PPCK). $\mathrm{C}_{4}$ photosynthesis results in more efficient carbon assimilation at high temperatures because its combination of morphological and biochemical features reduce photorespiration, a loss of $\mathrm{CO}_{2}$ that occurs during $\mathrm{C}_{3}$ photosynthesis at high temperatures [10]. PPDK regulatory protein (PPDKRP), a bifunctional serine/threonine kinase-phosphatase, catalyzes both the ADP-dependent inactivation and the Pidependent activation of PPDK [11].

The evolution of a novel biochemical pathway is based on the creation of new genes, or functional changes in existing genes. Gene duplication has been recognized as one of the principal mechanisms of the evolution of new genes. Genes encoding enzymes of the $\mathrm{C}_{4}$ cycle often belong to gene families having

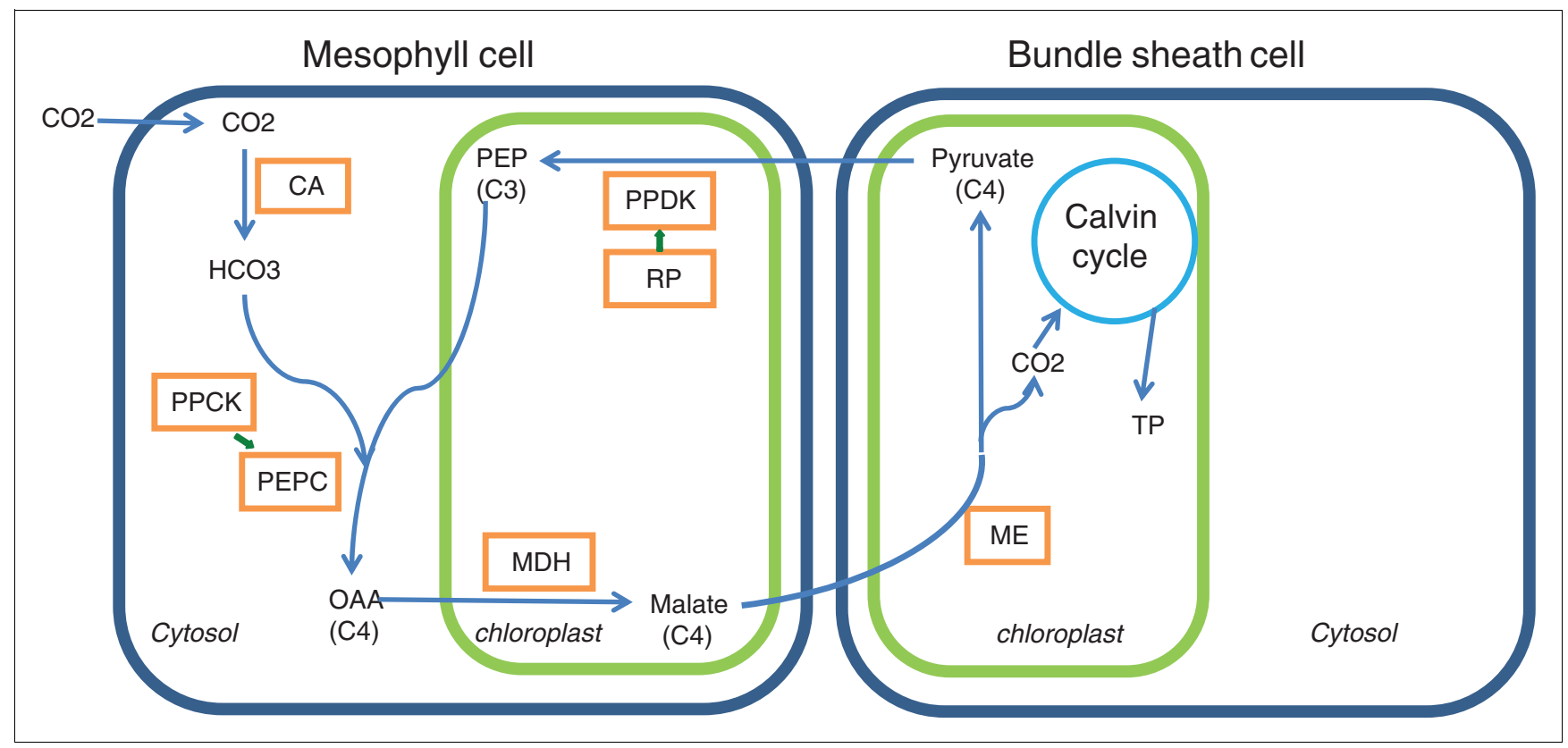

Figure I

The NADP-ME type of $\mathrm{C4}$ pathway in sorghum and maize. CA, carboxylating anhydrase; MDH, malate dehydrogenase; ME, malic enzyme; OAA, oxaloacetate; PEPC, phosphoenolpyruvate carboxylase; PPCK, PEPC kinase; PPDK, pyruvate orthophosphate dikinase; PPDK-RP, PPDK regulatory protein; TP, transit peptide. 
multiple copies. For example, in maize and sorghum, a single $\mathrm{C} 4 \mathrm{PEPC}$ gene and other non-C4 isoforms were discovered [12], whereas in Flaveria trinervia, a $\mathrm{C} 4$ eudicot, multiple copies of C4 PEPC genes were found [13]. These findings led to the proposition that gene duplication, followed by functional innovation, was the genetic foundation for photosynthetic pathway transformation [14].

All plant genomes, including grass genomes, have been enriched with duplicated genes derived from tandem duplications, single-gene duplications, and large-scale or wholegenome duplications [15-18]. A whole-genome duplication (WGD) occurred in a grass ancestor approximately 70 million years ago (mya), before the divergence of the panicoid, oryzoid, pooid, and other major cereal lineages [19,20]. A preliminary analysis of sorghum genome data suggested that duplicated genes from various sources have expanded the sizes of some families of $\mathrm{C}_{4}$ genes and their non- 4 isoforms [21]. However, different duplicated gene pairs often have divergent fates [22]. While most duplicated genes are lost, gene retention in some functional groups produces large gene families in plants $[15,19,20]$. Together with other lines of evidence, these have led to the interesting proposition of differential gene duplicability $[23,24]$, or duplication-resistance [25], due to possible gene dosage imbalance, which can be deleterious [26]. Even when duplicated genes survive, there is rarely strong evidence supporting possible functional innovation [27].

Most $\mathrm{C} 4$ plants are grasses, and it has been inferred that $\mathrm{C}_{4}$ photosynthesis first arose in grasses during the Oligocene epoch (24 to 35 mya) $[28,29]$. Sorghum and maize, thought to have diverged from a common ancestor approximately 12 to 15 mya [21], are both in the Andropogoneae tribe, which is entirely composed of $\mathrm{C} 4$ plants [8]. Sorghum, a NADP-MEtype $\mathrm{C}_{4}$ plant grown for food, feed, fiber and fuel, is the second grass and the first $\mathrm{C}_{4}$ plant with its full genome sequence available [21]. The first grass genome sequenced was rice, a C3 plant. The availability of two grass genome sequences using different types of photosynthesis provides a valuable opportunity to explore $\mathrm{C} 4$ pathway evolution. In the present research, by using a comparative genomic approach and phylogenetic analysis, we compared $\mathrm{C}_{4}$ genes and their non- $\mathrm{C}_{4}$ isoforms in sorghum, maize and rice. The aims of this study are to investigate: the role of gene duplication in the evolution of 44 enzyme genes; the role of adaptive evolution in $\mathrm{C} 4$ pathway formation; the long-standing hypothesis that a reservoir of duplicated genes has been a prerequisite of $\mathrm{C}_{4}$ pathway evolution [14]; and whether codon usage bias has contributed to $\mathrm{C}_{4}$ gene evolution, as previously suggested [30]. Our results will help to clarify the evolution of the $\mathrm{C} 4$ pathway and may benefit efforts to transform $\mathrm{C}_{3}$ plants, such as rice, to $\mathrm{C}_{4}$ photosynthesis [31].

\section{Results \\ PEPC enzyme genes}

Grass PEPC enzyme genes form a small gene family. There are five plant-type and one bacteria-type PEPC (Sbo3g008410 and Oso1g0110700) [32] gene isoforms in sorghum and rice, respectively, excepting two likely pseudogenized rice isoforms (Oso1g0208800, Oso9g0315700) having only 217 and 70 codons. There is one sorghum $\mathrm{C}_{4} \mathrm{PEPC}$ [33,34], Sb1og021330 (Table S1 in Additional data file 1). Previous characterization indicated that its transcripts are more than 20 times more abundant in mesophyll than in bundlesheath cells [35] (Table S2 in Additional data file 1).

By analysis of gene colinearity, we investigated how genome duplication has affected the PEPC gene families in rice and sorghum. The PEPC gene in rice that is most similar to the sorghum $\mathrm{C}_{4} \mathrm{PEPC}$ is Os01g0208700, sharing 73\% amino acid identity. This similarity raised the possibility that the two genes are orthologous. Although the two genes under consideration are not in colinear locations, single-gene translocation is not rare in grasses [36]. The outparalogs, homologs produced by WGD in the common ancestor of sorghum and rice, of the sorghum $\mathrm{C}_{4}$ PEPC gene are located at the expected homoeologous locations in both sorghum and rice (Sb04g008720 and Oso2g0244700). The rice gene Oso1g0208700 and the $\mathrm{C} 4$ genes are grouped together, and outparalogs (Oso2g0244700 and Sbo4g008720) of the sorghum $\mathrm{C}_{4}$ gene form a sister group on the phylogenetic tree. The pattern can be explained if Oso1g0208700 were orthologous to the sorghum $\mathrm{C}_{4}$ PEPC gene, implied by their high sequence similarity and shared high GC content (detailed below). In our view, the most parsimonious explanation of these data is that the oryzoid (rice) ortholog was translocated after the sorghum-rice (panicoid-oryzoid) divergence, then the panicoid (sorghum) ortholog was recruited into the $\mathrm{C}_{4}$ pathway. We cannot falsify a model invoking independent loss of alternative homeologs in sorghum (panicoids) and rice (oryzoids), respectively, although this model seems improbable in that such loss of alternative homoeologs has only occurred for approximately 1.8 to $3 \%$ of genome-wide gene duplicates in these taxa [21]. The other rice and sorghum PEPC genes form four orthologous pairs. Whether the genes from different orthologous groups are outparalogs could not be supported by colinearity inference associated with the pan-cereal genome duplication.

Grass PEPC genes show high GC content, like many other grass genes, apparently as a result of changes after the monocot-dicot split but before the radiation of the grasses [37]. The evolution of $\mathrm{C}_{4}$ PEPC genes in sorghum and maize was previously proposed to have been accompanied by GC elevation, resulting in codon usage bias [38]. We found that $\mathrm{C}_{4} \mathrm{PEPC}$ genes do have higher GC content than other sorghum and maize PEPC genes, especially at the third codon sites (GC3). The sorghum and maize $\mathrm{C}_{4}$ PEPC genes have a GC3 content of approximately $84 \%$, significantly higher than other genes 
in both species (Table $\mathrm{S}_{3}$ in Additional data file 1). The suspected rice ortholog Oso1g020870o has even higher $\mathrm{GC}_{3}$ content, approximately $92 \%$. In contrast, the GC3 content of all Arabidopsis PEPC genes is $<43 \%$. This shows that the higher GC content in the 44 PEPC genes may not be related to the evolution of $\mathrm{C}_{4}$ function, as discussed below.

$\mathrm{C}_{4}$ PEPC genes show evidence of adaptive evolution. To characterize the evolution of $\mathrm{C}_{4}$ PEPC genes, we aligned the sequences and constructed gene trees without involving the possible pseudogenized rice gene (Additional data file 2). We found the genes to be in two groups, with one containing plant-type and the other bacteria-type PEPC genes. Careful inspection suggested problems with the tree, for orthologous genes were not grouped together as expected. After removing the bacteria-type genes and rooting the subtree containing the $\mathrm{C}_{4}$ genes with Arabidopsis PEPC genes, we obtained a tree in which orthologs are grouped together as expected (Figure 2a). The sorghum and maize $\mathrm{C}_{4}$ genes are on a remarkably long branch, suggesting that they are rapidly evolving (a)

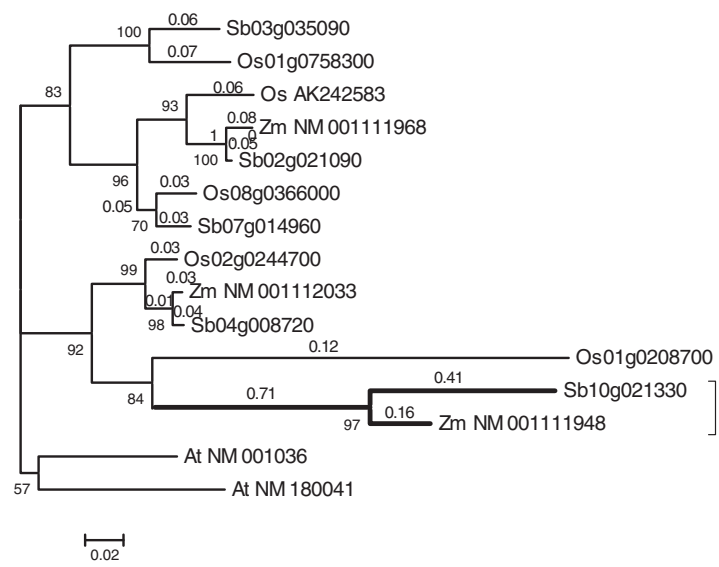

(c)

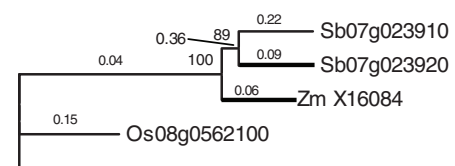

At NM 180883

(e)

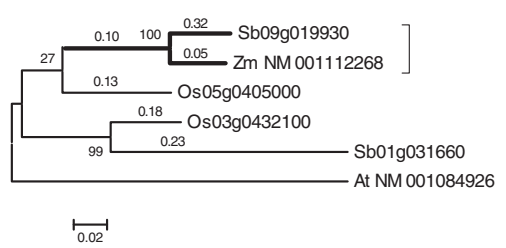

(f)

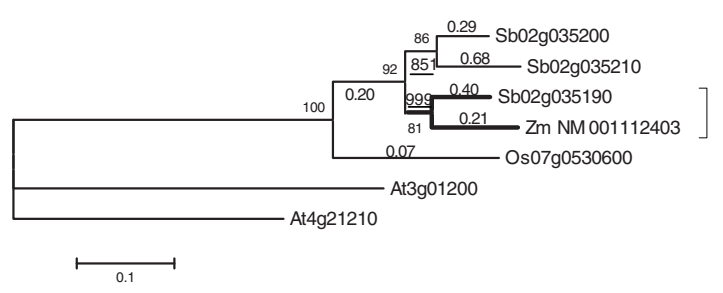

(b)

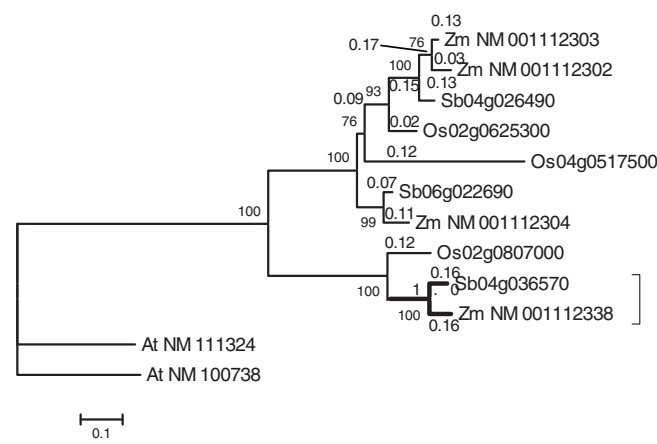

(d)

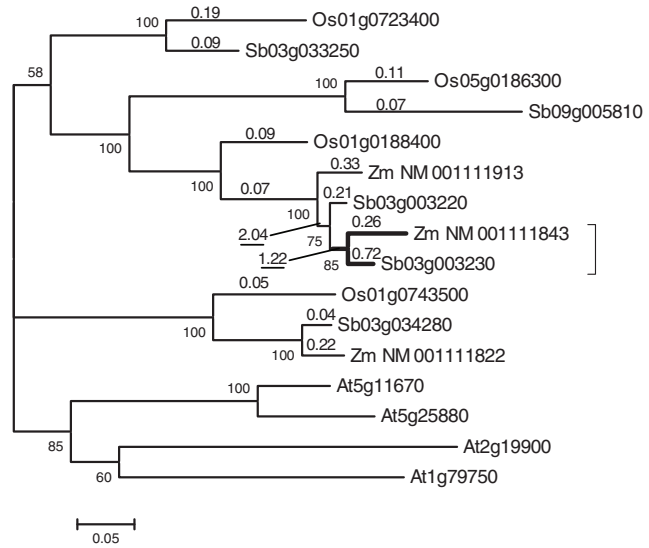

(g)

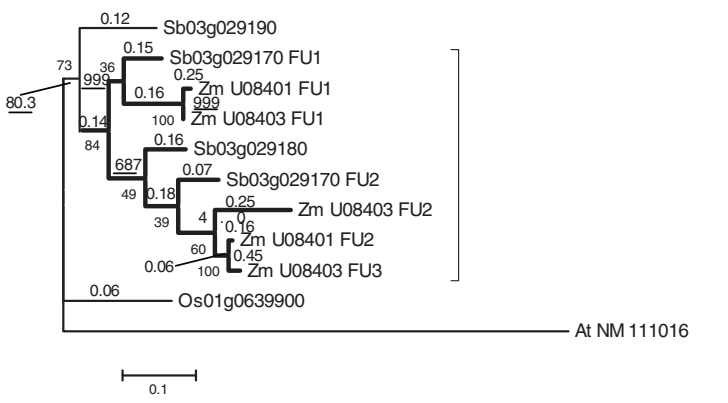

Figure 2

Phylogeny of C4 enzyme genes and their isoforms in sorghum, rice, maize and Arabidopsis. Thick branches show C4 enzyme genes. Bootstrap percentage values are shown as integers; Ka/Ks ratios are shown as numbers with fractions, or underlined when $>I$. In the gene IDs, Sb indicates Sorghum bicolor, Os indicates Oryza sativa, Zm indicates Zea mays, and At indicates Arabidopsis thaliana. (a) PEPC; (b) PPCK; (c) NADP-MDH; (d) NADP-ME; (e) PPDK; (f) PPDK-RP; (g) CA. 
compared to the other genes, and implying possible adaptive selection during the evolution of the $\mathrm{C} 4$ pathway, consistent with a previous proposal [39].

Maximum likelihood analysis supports possible adaptive evolution of $\mathrm{C}_{4}$ PEPC genes. First, characterization of nonsynonymous nucleotide substitution rates $(\mathrm{Ka})$ supports rapid evolution of the $\mathrm{C}_{4}$ genes and their rice ortholog. Under a free-parameter model, Ka values are $>0.048$ on branches leading to $\mathrm{C} 4$ genes and their rice ortholog after the rice-sorghum split, as compared to $\leq 0.02$ on branches leading to the non-C4 isoforms. Second, the $\mathrm{C}_{4}$ genes may have been positively selected. The $\mathrm{Ka} / \mathrm{Ks}$ ratio is nearly tenfold higher (0.71) on the branch leading to the last common ancestor of the sorghum and maize $\mathrm{C}_{4}$ genes than on other branches after the rice-sorghum split $(\leq 0.08)$. Though the ratio is $<1$, we propose that the striking difference in $\mathrm{Ka} / \mathrm{Ks}$ between $\mathrm{C}_{4}$ and non-C4 genes may be evidence of positive selection in the $\mathrm{C}_{4}$ genes for the following reasons: the criterion $\mathrm{Ka} / \mathrm{Ks}>1$ has been proposed to be unduly stringent to infer positive selection [40]; the maximum likelihood analysis is conservative, as reported previously [27]; and the similar slow evolutionary changes in all non-C4 genes in sorghum, maize and rice (Figure 1a) imply elevated rates in the $\mathrm{C}_{4}$ genes, rather than purifying selection in the non-C4 genes.

C4 PEPC genes show elevated and aggregated amino acid substitutions especially in function-specific regions, providing further evidence of adaptive evolution. Comparison to their outparalogs and their nearest outgroup sequence suggests that $\mathrm{C}_{4}$ PEPC genes have accumulated approximately 100 putative substitutions over their full length (Table 1), far more than non-C4 PEPC genes. The substitutions are referred to as putative since we cannot rule out the possibility of parallel and reverse mutations. However, the extremely significant difference strongly supports divergent evolution of $\mathrm{C}_{4}$ and non-C4 PEPC genes. The amino acid substitutions are not uniformly distributed along the lengths of the $\mathrm{C}_{4}$ genes (Table $\mathrm{S}_{4}$ in Additional data file 1), but concentrated in the carboxy-terminal half, including the critical mutation S780 (the serine at position 780 of the maize 44 PEPC protein that is essential to relieving feedback inhibition by malate [41]). This is consistent with previous findings [42].

Surprisingly, Oso1g0208700 has also accumulated significantly more mutations than expected, and has a relatively larger selection pressure than other non-C4 PEPC genes, implying that it may also be under adaptive selection (Table 1; Table $\mathrm{S}_{4}$ in Additional data file 1), as further discussed below.

\section{PPCK enzyme genes}

PPCK gene families have been enriched by duplication events, including the pan-cereal WGD and tandem duplication. We identified three PPCK gene isoforms in both sorghum and rice, respectively (Table $\mathrm{S} 1$ in Additional data file 1 ), which are in one-to-one correspondence in expected colinear locations between the two species (Figure 2b). These rice and sorghum isoforms correspond to four maize isoforms (ZmPPCK1 to ZmPPCK4; Figure 2b), with $\mathrm{ZmPPCK} 2$ and $\mathrm{ZmPPCK}_{3}$ likely produced in maize after its divergence from a lineage shared with sorghum. The sorghum $\mathrm{C}_{4}$ PPCK is encoded by Sbo4g036570, and its maize ortholog is ZmPPCK1. Their $\mathrm{C}_{4}$ nature is supported by evidence that their expression is lightinduced and their transcripts are more abundant in mesophyll than bundle-sheath cells [30]. In contrast, the expression of sorghum and maize non-C4 isoforms is not light- but cycloheximide-affected [30]. The outparalogs of the sorghum C4 gene and its rice ortholog were likely lost before the two species split, whereas the other four isoforms are outparalogs.

Maximum likelihood analysis and inference of aggregated amino acid substitutions found no evidence of adaptive selection during $\mathrm{C}_{4}$ PPCK gene evolution (Table $\mathrm{S} 4$ in Additional data file 1).

Consistent with a previous report [30], all studied grass PPCK genes have extremely high GC content, with a GC3 content from 88 to $97 \%$ (Table 33 in Additional data file 1). The grass $\mathrm{C}_{4}$ and non-C4 PPCK genes have similar GC content.

\section{NADP-MDH enzyme genes}

There are two NADP-MDH enzyme genes in sorghum (Table $\mathrm{S} 1$ in Additional data file 1), the non-C4 gene Sbo7g023910 and the C4 gene Sbo7g023920, tandemly located as previously reported [43]. They have only one homolog in both rice and maize [44], with the rice homolog (Oso8g0562100) at the expected colinear location. This suggests that the NADPMDH WGD outparalog was lost before the sorghum-rice split. Each of the sorghum tandem genes has an ortholog in Vetiveria and Saccharum, respectively [44], suggesting that the tandem duplication occurred before the divergence of sorghum and Vetiveria, but after the sorghum-maize split, an inference further supported by gene tree analysis in that they are more similar to one another than to the single maize homolog (Figure 2c).

The C4 NADP-MDH gene shows an interesting mode of adaptive evolution. Though the $\mathrm{C} 4 \mathrm{NADP}-\mathrm{MDH}$ genes have accumulated more mutations than non-C4 genes (Table $\mathrm{S}_{4}$ in Additional data file 1), neither maximum likelihood analysis nor the inference of aggregated amino acid substitution suggest adaptive selection. However, the sorghum $\mathrm{C}_{3}$ and $\mathrm{C}_{4}$ genes were likely to have been produced by an ancestral $\mathrm{C}_{4}$ gene through duplication. One of the duplicates may have lost its $\mathrm{C}_{4}$ function as it is not light-induced and only constitutively expressed [43].

The NADP-MDH genes are chloroplastic. A chloroplast transit peptide (cTP) having approximately 40 amino acids is identified in all the genes from grasses and Arabidopsis (Additional data file 3). This indicates that the cTP was present in the common ancestor of angiosperms. Non-chloro- 
Table I

Aggregated amino acid substitution analysis results

\begin{tabular}{|c|c|c|c|c|c|c|c|c|}
\hline Gene I & Gene 2 & Outgroup & $\begin{array}{l}\text { Alignment } \\
\text { length }\end{array}$ & $\begin{array}{l}\text { Alignment length } \\
\text { without gaps }\end{array}$ & $\begin{array}{l}\text { Average } \\
\text { identity }\end{array}$ & $\begin{array}{c}\text { Overall substitution } \\
\text { number in gene I }\end{array}$ & $\begin{array}{l}\text { Overall substitution } \\
\text { number in gene } 2\end{array}$ & $P$-value \\
\hline \multicolumn{9}{|l|}{ PEPC } \\
\hline Sblog021330 & Os02g0244700 & Os0lg0758300 & 972 & 958 & 0.76 & 110 & 26 & $5.89 \mathrm{E}-13$ \\
\hline Zm_NM_00III 968 & Os02g0244700 & Os0Ig0758300 & 971 & 968 & 0.78 & 92 & 33 & I.3IE-07 \\
\hline SbIOg02I330 & Os02g0244700 & Sb03g035090 & 972 & 958 & 0.76 & 117 & 28 & $1.46 \mathrm{E}-13$ \\
\hline Zm_NM_00III 968 & Os02g0244700 & Sb03g035090 & 971 & 968 & 0.77 & 104 & 34 & $2.54 \mathrm{E}-09$ \\
\hline \multicolumn{9}{|l|}{ PPCK } \\
\hline Sb04g036570 & Os02g0807000 & Sb06g022690 & 309 & 284 & 0.65 & 15 & 14 & $8.53 \mathrm{E}-0 \mathrm{I}$ \\
\hline Zm_NM_00III 2338 & Os02g0807000 & Sb06g022690 & 309 & 281 & 0.63 & 18 & 11 & I.94E-0I \\
\hline \multicolumn{9}{|l|}{ CA } \\
\hline U08403_FU3 & Os0Ig0639900 & Sb03g029190.I & 272 & 201 & 0.75 & 19 & 18 & $8.69 \mathrm{E}-0 \mathrm{I}$ \\
\hline U08403_FU2 & Os0lg0639900 & Sb03g029190.I & 273 & 200 & 0.73 & 20 & 18 & $7.46 \mathrm{E}-0 \mathrm{I}$ \\
\hline U08403_FUI & Os0 Ig0639900 & Sb03g029190.I & 273 & 202 & 0.79 & 13 & 18 & $3.69 \mathrm{E}-0 \mathrm{I}$ \\
\hline U0840I_FU2 & Os0Ig0639900 & Sb03g029190.I & 272 & 201 & 0.75 & 18 & 18 & $1.00 \mathrm{E}+00$ \\
\hline U0840I_FUI & Os0lg0639900 & Sb03g029190.I & 273 & 202 & 0.78 & 14 & 18 & $4.80 \mathrm{E}-0 \mathrm{I}$ \\
\hline Sb03g029170_FU2 & Os0Ig0639900 & Sb03g029190.I & 272 & 201 & 0.78 & 14 & 16 & $7.15 \mathrm{E}-01$ \\
\hline Sb03g029170_FUI & Os0Ig0639900 & Sb03g029190.I & 273 & 201 & 0.80 & 11 & 20 & I.06E-0I \\
\hline Sb03g029180 & Os0Ig0639900 & Sb03g029190.I & 274 & 202 & 0.80 & 11 & 19 & I.44E-0I \\
\hline U08403_FU3 & Os0Ig0639900 & At_NM_III016 & 293 & 201 & 0.50 & 14 & 13 & 8.47E-0I \\
\hline U08403_FU2 & Os0Ig0639900 & At_NM_III016 & 293 & 200 & 0.49 & 16 & 14 & $7.15 \mathrm{E}-01$ \\
\hline U08403_FUI & Os0Ig0639900 & At_NM_III016 & 293 & 202 & 0.50 & 10 & 15 & 3.|7E-0I \\
\hline U0840I_FU2 & Os0Ig0639900 & At_NM_III016 & 293 & 201 & 0.50 & 12 & 13 & 8.4IE-0I \\
\hline U0840I_FUI & Os0lg0639900 & At_NM_III016 & 293 & 202 & 0.50 & 11 & 15 & $4.33 \mathrm{E}-0 \mathrm{I}$ \\
\hline Sb03g029170_FU2 & Os0Ig0639900 & At_NM_III016 & 293 & 201 & 0.50 & 10 & 10 & $1.00 \mathrm{E}+00$ \\
\hline Sb03g029I70_FUI & Os0 Ig0639900 & At_NM_III016 & 293 & 201 & 0.50 & 9 & 14 & 2.97E-0I \\
\hline Sb03g029I80 & Os0Ig0639900 & At_NM_III016 & 293 & 202 & 0.50 & 8 & II & 4.9IE-0I \\
\hline \multicolumn{9}{|l|}{ PPDK } \\
\hline Sb09g019930 & Os05g0405000 & Os03g0432100 & 949 & 946 & 0.83 & 42 & 28 & $9.43 \mathrm{E}-02$ \\
\hline Zm_NM_00IIII2268 & Os05g0405000 & Os03g0432100 & 950 & 944 & 0.83 & 44 & 28 & $5.93 \mathrm{E}-02$ \\
\hline Sb09g019930 & Os05g0405000 & Sb0 Ig031660 & 958 & 946 & 0.76 & 37 & 15 & $2.28 \mathrm{E}-03$ \\
\hline Zm_NM_00III 2268 & Os05g0405000 & Sb0Ig031660 & 961 & 942 & 0.78 & 32 & 18 & 4.77E-02 \\
\hline \multicolumn{9}{|l|}{ NADP-MDH } \\
\hline Sb07g023920 & Os08g0562100 & At_NM_I80883 & 443 & 427 & 0.77 & 22 & 19 & $6.39 \mathrm{E}-0 \mathrm{I}$ \\
\hline Sb07g023910 & Os08g0562100 & At_NM_I80883 & 443 & 432 & 0.75 & 25 & 16 & $1.60 \mathrm{E}-0 \mathrm{I}$ \\
\hline ZM_XI6084 & Os08g0562100 & At_NM_I80883 & 443 & 430 & 0.75 & 25 & 13 & $5.16 \mathrm{E}-02$ \\
\hline \multicolumn{9}{|l|}{ NADP-ME } \\
\hline Sb03g003230 & Os0Ig0I88400 & Os05g0I86300 & 642 & 633 & 0.80 & 46 & 16 & I.39E-04 \\
\hline Sb03g003230 & Os0Ig0I88400 & Sb09g0058I0 & 642 & 633 & 0.80 & 41 & 20 & 7.17E-03 \\
\hline Sb03g003220 & Os0Ig0I88400 & Os05g0I86300 & 650 & 635 & 0.84 & 23 & 15 & $1.94 \mathrm{E}-0 \mathrm{I}$ \\
\hline ZM_NM_001IIII843 & Os0Ig0I88400 & Os05g0I86300 & 641 & 634 & 0.80 & 47 & 16 & $9.40 \mathrm{E}-05$ \\
\hline ZM_NM_0011II913 & Os0Ig0I88400 & Os05g0|86300 & 668 & 633 & 0.84 & 26 & 15 & $8.58 \mathrm{E}-02$ \\
\hline \multicolumn{9}{|l|}{ PPDK-RP } \\
\hline Sb02g035190 & Os07g0530600 & At4g21210 & 474 & 426 & 0.58 & 37 & 17 & $6.00 \mathrm{E}-03$ \\
\hline Zm_NM_00IIII2403 & Os07g0530600 & At4g21210 & 474 & 423 & 0.57 & 33 & 23 & I.80E-0I \\
\hline $\mathrm{Sb02g035190}$ & Sb02g035200 & Os07g0530600 & 476 & 408 & 0.69 & 19 & 22 & $6.40 \mathrm{E}-0 \mathrm{I}$ \\
\hline Sb02g035190 & Sb02g035210 & Os07g0530600 & 483 & 384 & 0.69 & 21 & 22 & 8.70E-0I \\
\hline Zm_NM_00III 2403 & Sb02g035200 & Os07g0530600 & 472 & 416 & 0.67 & 25 & 22 & $6.60 \mathrm{E}-0 \mathrm{I}$ \\
\hline Zm_NM_00III 2403 & Sb02g035210 & Os07g0530600 & 482 & 389 & 0.68 & 25 & 25 & $1.00 \mathrm{E}+00$ \\
\hline
\end{tabular}


plastic NADP-MDH genes identified in the sorghum genome share less than $40 \%$ protein sequence similarity with the chloroplastic ones.

All of the grass NADP-MDH enzyme genes studied have elevated GC content compared to the Arabidopsis ortholog, especially regarding $\mathrm{GC}_{3}$ (50\% versus 40\%; Table $\mathrm{S}_{3}$ in Additional data file 1). The grass $\mathrm{C}_{4}$ genes have slightly higher GC content than the non-C4 genes.

\section{NADP-ME enzyme genes}

The NADP-ME gene family has been gradually expanding due to tandem duplication and the pan-cereal WGD. We identified five and four NADP-ME enzyme genes in sorghum and rice, respectively (Table $\mathrm{S} 1$ in Additional data file 1 ). The sorghum $\mathrm{C}_{4}$ gene is Sbo3goo3230, whose transcript is abundant in bundle-sheath but not mesophyll cells [35] (Table S2 in Additional data file 1). The $\mathrm{C}_{4}$ gene has a tandem duplicate that may have been produced before the sorghum-maize split based on gene similarity and tree topology (Figure 2d). The tandem genes share the same rice ortholog (Oso1g0188400) at the expected colinear location, and their WGD duplicates can be found at the expected colinear location in both species. The other sorghum and rice NADP-ME genes form two orthologous pairs, having also remained at the colinear locations predicted based on the pan-cereal duplication.

Maximum likelihood analysis indicates that the sorghum and maize C4 NADP-ME genes are under positive selection. The branches leading to their two closest ancestral nodes have a $\mathrm{Ka} / \mathrm{Ks}$ ratio $>1\left(P\right.$-value $\left.=8 \times 10^{-10}\right)$. Moreover, the $\mathrm{C}_{4}$ genes have a significant abundance of amino acid substitutions (Table 1; Table S4 in Additional data file 1). The most affected regions in sorghum and maize overlap with one another, from residue 141 to residue 230 in sorghum, and from residue 69 to residue 181 in maize.

The grass NADP-ME genes have higher GC content than their Arabidopsis homologs (Table $\mathrm{S}_{3}$ in Additional data file 1). The highest GC content ( $\mathrm{GC}_{3}>82 \%$ ) is found not in the $\mathrm{C}_{4}$ genes but in their outparalogs, Sboggoo5810 and Oso5g0186300.

The $\mathrm{C} 4$ genes, their tandem paralogs in sorghum and maize, and their rice ortholog all share an approximately 39 amino acid cTP that is absent from their WGD paralogs in grasses, or homologs in Arabidopsis. This seems to suggest that the cTP was acquired by one member of a duplicated gene pair after the pan-grass WGD but before the sorghum-rice divergence.

\section{PPDK enzyme genes}

Sorghum and rice both have two PPDK enzyme genes (Table $\mathrm{S} 1$ in Additional data file 1). The sorghum $\mathrm{C}_{4}$ PPDK gene (Sbogg019930) is identified based on its approximately 90\% amino acid identity with the maize $\mathrm{C}_{4}$ gene. Its transcript is abundant in mesophyll rather than bundle-sheath cells [35]
(Table S2 in Additional data file 1). Its rice ortholog (Oso5g0405000) can be inferred based on both gene trees (Figure 2e) and gene colinearity. The other rice and sorghum isoforms are orthologous to one another. Whether the four isoforms are outparalogs produced by the WGD could not be determined by gene colinearity inference due to possible gene translocations. However, synonymous nucleotide substitution rates and gene tree topologies support that the rice and sorghum paralogs were produced before the two species diverged, and approximately at the time of the pan-cereal WGD.

There are two PPDK genes in maize [10]. One of them encodes both a $\mathrm{C}_{4}$ transcript and a cytosolic transcript, controlled by distinct upstream regulatory elements [45]. The $\mathrm{C}_{4}$ copy has an extra exon encoding a cTP at a site upstream of the cytosolic gene [46]. We found that the sorghum $\mathrm{C}_{4}$ PPDK gene is highly similar to its maize counterpart along their respective full lengths, indicating their origin in a common maize-sorghum ancestor. The other maize PPDK gene has only a partial DNA sequence and, therefore, has been avoided in the present evolutionary analysis. A similarity search against the maize bacterial artificial chromosome (BAC) sequences indicates that it is on a different chromosome (chromosome 8) from the $\mathrm{C}_{4}$ gene (chromosome 6). The maize counterpart of the other sorghum PPDK isoform has not yet been identified in sequenced BACs.

The C4 PPDK genes may have experienced adaptive evolution. While maximum likelihood analysis did not find evidence of adaptive evolution of $\mathrm{C}_{4}$ PPDK genes (Figure 2e), the $\mathrm{C} 4$ genes have accumulated significantly or nearly significantly more amino acid substitutions than their rice orthologs, particularly in the region from approximately residue 207 to approximately residue 620 (Table 1; Table S4 in Additional data file 1).

All grass PPDK genes have higher GC content than their Arabidopsis homologs (Table $\mathrm{S}_{3}$ in Additional data file 1), with the $\mathrm{C}_{4}$ genes themselves being highest in $\mathrm{GC}$ content ( $\mathrm{GC}_{3}$ content approximately 61 to $70 \%$ ).

All of the characterized PPDK isoform sequences from grasses and Arabidopsis share an approximately 20 amino acid cTP (Additional data file 3), suggesting its origin before the monocot-dicot split.

\section{PPDK-RP enzyme genes}

Tandem duplication contributed to the expansion of PPDK$\mathrm{RP}$ genes. Using the maize PPDK-RP gene sequence as a query, we determined its possible sorghum ortholog, Sbo2g035190, which has two tandem paralogs. Their rice ortholog, Oso7g053060o, was identified in the anticipated colinear region. However, we failed to find their WGD outparalogs in both sorghum and rice, suggesting possible gene loss in their common ancestor. 
(a)

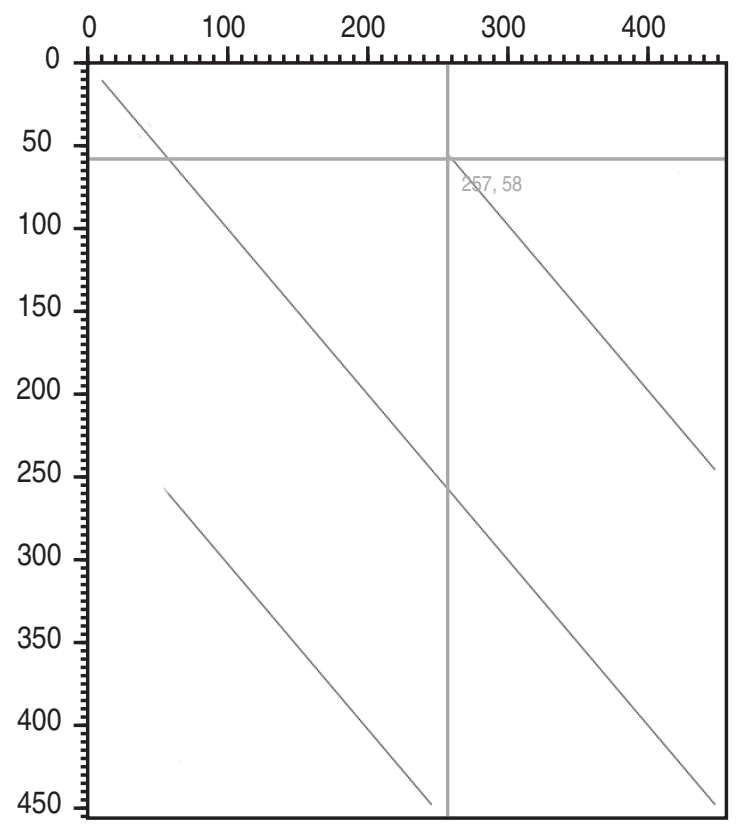

(d)

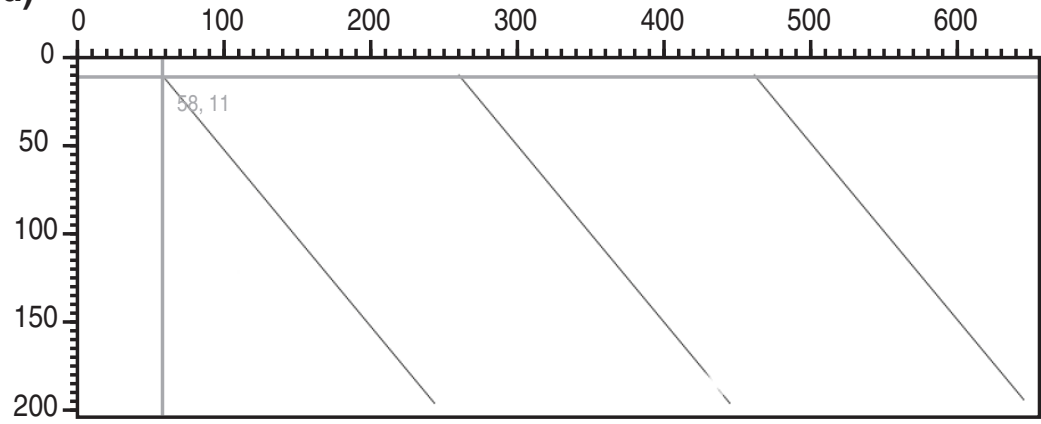

(b)
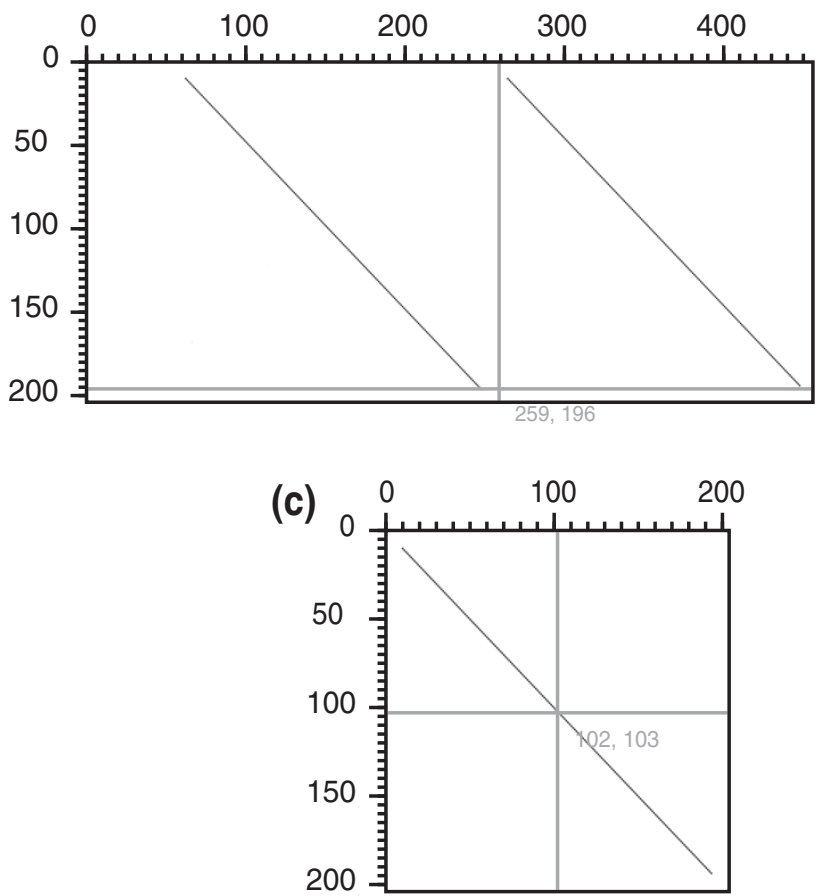

(e)

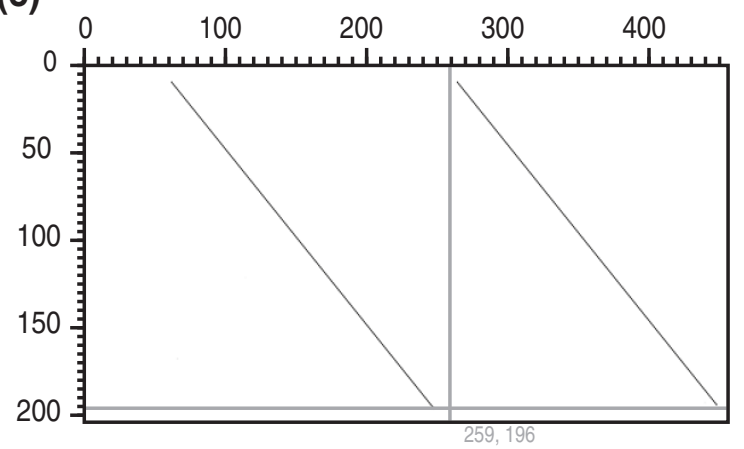

Figure 3

Dotplots between sorghum and maize CA enzyme protein sequences. (a) Self-comparison of protein sequence of Sb03g029170. (b) Sb03g029170 (horizontal) and Sb03g029180 (vertical); (c) Sb03g029190 (horizontal) and Sb03g029180 (vertical); (d) maize U08403 (horizontal) and Sb03g029180 (vertical); (e) maize U0840 (horizontal) and Sb03g029I80 (vertical). 
Gene trees indicate that the tandem duplication events may have occurred before the sorghum-maize divergence, but after the sorghum-rice divergence (Figure 2f). Maximum likelihood analysis suggests that both lineages leading to the maize PPDK-RP gene and its sorghum ortholog, and other isoforms, have been under significant positive selection $(\mathrm{Ka} /$ Ks $>>1, P$-value $=2.5 \times 10^{-8}$ ), implying possible functional changes in both lineages. Compared to their rice ortholog, sorghum and maize PPDK-RP genes have accumulated significantly more amino acid substitutions (Table 1; Table $\mathrm{S}_{4}$ in Additional data file 1), providing supporting evidence for functional innovation.

Both the $\mathrm{C}_{4}$ and non-C4 PPDK-RP genes in sorghum have similar GC content (GC3 content approximately 57 to $60 \%$ ), while the maize PPDK-RP gene has higher GC content ( $\mathrm{GC}_{3}$ content approximately 67\%), especially in the third codon sites (Table S3 in Additional data file 1). All these grass PPDKRP genes show higher GC content than their Arabidopsis homologs.

\section{CA enzyme genes}

Tandem duplication has profoundly affected the evolution of CA genes. There are two types of CA enzymes, the alpha and beta types in sorghum [21], and $\mathrm{C}_{4} \mathrm{CA}$ genes are the beta type [47]. Here, we focus on beta-type CA genes. Our analysis indicates that there are four beta-type CA enzyme gene isoforms in sorghum, forming a tandem gene cluster with the same transcriptional orientation, on chromosome 3 (Figure $3 \mathrm{a}$; Table S1 in Additional data file 1). Among them are two possible C4 genes (Sbo3g029170 and Sbo3g029180), which were shown by previous analysis of transcript abundance to be highly expressed in mesophyll but not bundle-sheath cells (Table S2 in Additional data file 1). The other two genes include one non-C4 gene (Sbo3go29190) and one probable pseudogene (Sbo3g029200) with only truncated coding sequence, a large DNA insertion in its second exon, and accumulated point mutations. These tandem genes have a common rice ortholog (Oso1go639900) at the expected colinear location, indicating that gene family expansion has occurred in sorghum (and maize; see below) since divergence from rice. The WGD outparalogs were not identified in either

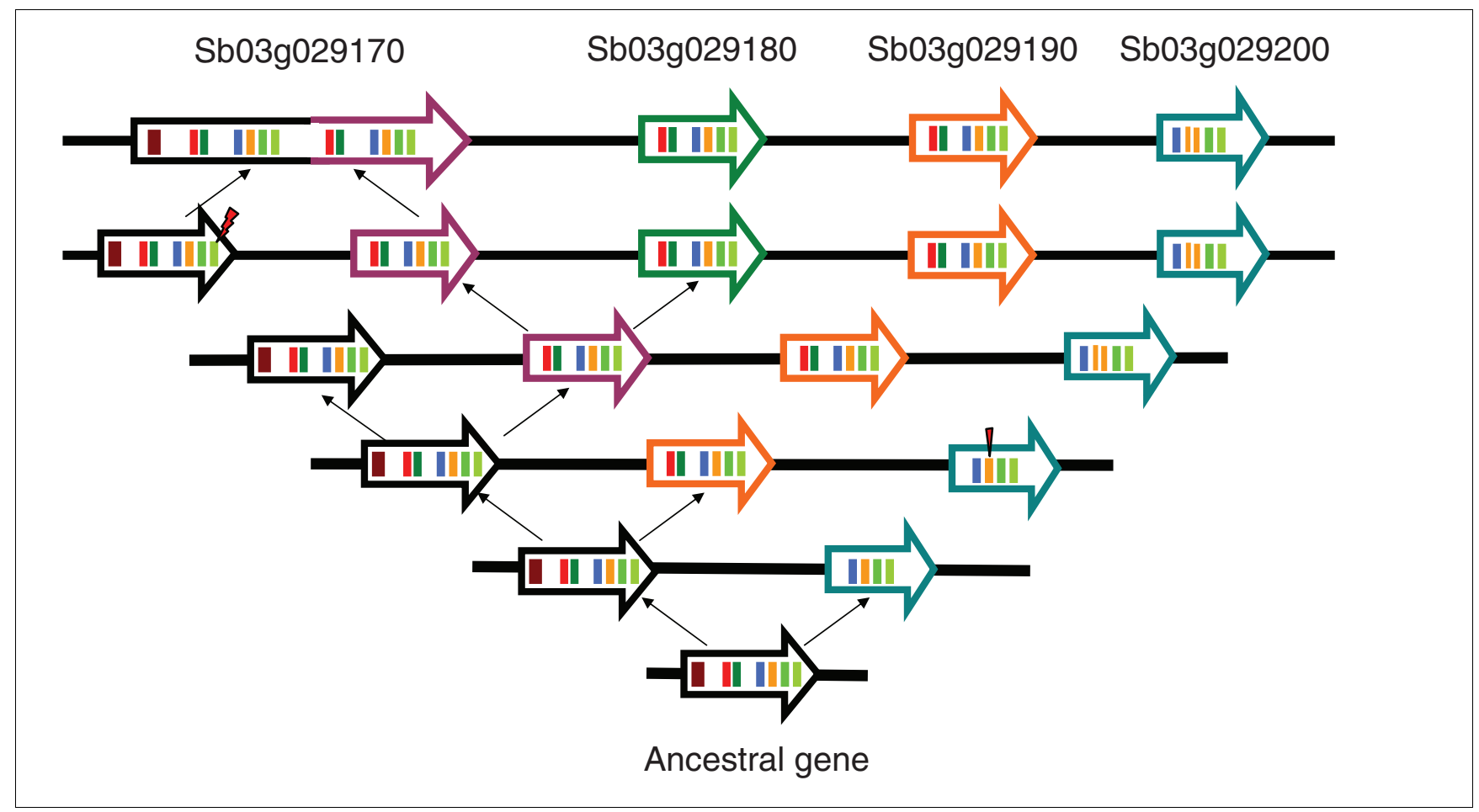

Figure 4

Tandem duplication and fusion of CA genes in sorghum. Postulated evolution of sorghum CA genes through four tandem duplication events and a gene fusion event is displayed. We show distribution and structures of CA genes, and their peptide-encoding exons, on sorghum chromosome 3. Genes are shown as the large arrows with differently colored outlines and exons are shown as colored blocks contained in the arrows. Homologous exons are in the same color. A chloroplast transit peptide is in dark red. A tandem duplication event is shown by two small black arrows pointing in divergent directions, and a gene fusion event is shown by two small black arrows pointing in convergent directions. A new gene produced by tandem duplication is shown with an arrow in a new color not used by the ancestral genes. A gene produced by fusion of two neighboring genes is shown as a bipartite structure, each part with the color of one of the fused genes. A stop codon mutation is shown by a lightning-bolt symbol, and an exon-splitting event by a narrow triangle. 
genome, implying possible gene loss after the WGD and before the rice-sorghum split.

The two sorghum $\mathrm{C}_{4} \mathrm{CA}$ genes differ in cDNA length [35]. We found that the larger $\mathrm{C}_{4} \mathrm{CA}$ gene may have evolved by fusing two neighboring CA genes produced by tandem duplication. In spite of possible alternative splicing programs, Sbo3g029170 has a gene length of approximately $10.4 \mathrm{kbp}$ and includes 13 exons, as compared to $4.5 \mathrm{kbp}$ in length and 6 exons for Sbo3g029180. Pairwise dotplots between Sbo3g029170 and Sbo3g029180 show the former has an internal repeat structure absent from the latter (Figure $3 \mathrm{ab}$; Additional data file 4). The duplication involves the last six of seven exons and intervening introns 1 to 6 of the ancestral gene (Figure 4a). Comparatively, the other sorghum genes have only exons 2 to 7 , assumed to be a functional unit, both lacking the first exon in Sbo3g029170, which encodes a cTP. This implies that several duplication events have recursively produced extra copies of the functional unit. Some functional units act as independent genes, while the other fused with the complete one to form an expanded gene including two functional units. We found that this fusion involved mutation of the stop codon in the leading gene. Each functional unit starts with an ATG codon, which we infer may increase the possibility of alternative splicing. This inference is supported by the finding that Sbo3g029170 may have two distinct transcripts, identified by cDNA HHU69 and HHU22, respectively (Table S2 in Additional data file 1). The two transcripts have distinct lengths, 2,100 and 1,200 bp, respectively, with the expression of the longer one being light-inducible and $\mathrm{C}_{4}$-related but the shorter one not [35]. The non-C4 gene, Sbo3go29190, has a normal structure (Figure 3c) and the pseudogene, Sbo3g029200, has a truncated structure.

The tandem duplication and gene fusion are shared by sorghum and maize, and maize furthermore has additional duplication. Interestingly, we found that the maize CA enzyme genes have two and three functional units, respectively (Figure 3de; Additional data file 4), implying further DNA sequence duplication and gene fusion in the maize lineage. Mutation of stop codons was also found in the leading gene sequences. Rice and Arabidopsis genes have only one functional unit preceded by a cTP.

To clarify the evolution of CA genes, we performed a phylogenetic analysis of the functional units (Figure 2f). The first functional units from sorghum and maize genes are grouped together, the second and third maize units and that of Sbo3g02918o were in another group, and the rice gene and non-C4 sorghum gene Sbo3go29190 were outgroups. This suggests the origin of the extra functional units to be after the Panicoideae-Ehrhartoideae divergence but before the sorghum-maize divergence, and continuing in the maize lineage. A possible evolutionary process in sorghum is illustrated in Figure 4b.
A gene tree of functional units suggested that $\mathrm{C}_{4} \mathrm{CA}$ genes may have been affected by positive selection. According to the free-parameter model of the maximum likelihood approach, we found that the two functional unit groups revealed above may have experienced positive selection, in that $\mathrm{Ka} / \mathrm{Ks}>1$ (Figure 2f), though this possibility is not significantly supported by statistical tests or by amino acid substitution analysis (Table $\mathrm{S}_{4}$ in Additional data file 1).

Excepting the possibly pseudogenized sorghum CA gene, the grass isoforms have very high GC content (GC3 content 82 to 92\%), much higher than that of the Arabidopsis orthologs (Table $\mathrm{S}_{3}$ in Additional data file 1). The non-C4 gene, Sbo3g029190, rather than any of the $\mathrm{C}_{4}$ genes, has the highest GC content in sorghum.

\section{Discussion \\ Gene duplication and C4 pathway evolution}

In the case of the $\mathrm{C} 4$ pathway, the evolution of a novel biological pathway required the availability of gene families with multiple members, in which modification of both expression patterns and functional domains led to new adaptive phenotypes. An intuitive idea is that genetic novelty formation is simplified by exploiting available 'construction bricks', and the pathway genes that we are aware of were either 'subverted' from existing functions or were created through modification of existing genes. Three mechanisms of new gene formation have been proposed [48]: duplication of pre-existing genes followed by neofunctionalization; creation of mosaic genes from parts of other genes; and de novo invention of genes from DNA sequences.

Duplicated genes have long been suggested to contribute to the evolution of new biological functions. As early as 1932, Haldane suggested that gene duplication events might have contributed new genetic materials because they create initially identical copies of genes, which could be altered later to produce new genes without disadvantage to the organism [49]. Ohno proposed that gene duplication played an essential role in evolution [50], pointed out the importance that WGD might have had on speciation, and hypothesized that at least one WGD event facilitated the evolution of vertebrates [51]. This hypothesis has been supported by evidence from various gene families, and from the whole genome sequences of several metazoans $[52,53]$. Plant genomes have experienced recurring WGDs [15,54-57], and perhaps all angiosperms are ancient polyploids [54]. These polyploidy events contribute to the creation of important developmental and regulatory genes [58-61], and may have played an important role in the origin and diversification of the angiosperms [62]. About 20 million years before the divergence of the major grass clades $[19,20]$, the ancestral grass genome was affected by a WGD, possibly preceded by still more ancient duplication events $[17,63]$. It is tempting to link this WGD to the evolutionary success of grasses, now including more than 
10,000 species and covering about $20 \%$ of the Earth's land surface [64], though such a link has not yet been adequately justified.

Gene duplication has been related to the evolution of the $\mathrm{C}_{4}$ pathway, based on the finding that $\mathrm{C}_{4}$ enzyme genes are usually from families having multiple copies [14]. Consequently, an ability to create and maintain large numbers of duplicated genes has been supposed to be one precondition for certain taxa to develop $\mathrm{C}_{4}$ photosynthesis $[6,14]$. It was even suggested that evolution of the $\mathrm{C} 4$ pathway was largely a story of gene duplication while plants were still in the ancestral $\mathrm{C}_{3}$ state [14].

Different genes in the $\mathrm{C}_{4}$ pathway were affected in different ways and at different times by gene duplication. Firstly, the approximately 70-mya pan-cereal WGD enriched the reservoir of some genes but not others. For example, in sorghum, both duplicated copies were preserved for PEPC and NADP$\mathrm{ME}$ genes, and one of the copies of each gene produced by WGD was later recruited into the $\mathrm{C} 4$ pathway. This finding highlights the contribution of WGD to the evolution of $\mathrm{C}_{4}$ photosynthesis. However, for NADP-MDH, CA, PPDK-RP and PPCK enzyme genes, one of the WGD duplicates was probably lost. For CA, NADP-ME, and PPDK-RP, tandem gains of new genes after the sorghum-rice divergence appears to have preceded $\mathrm{C} 4$ evolution. This seems to suggest that earlier availability of the pan-cereal duplicated copies was not by itself sufficient to initiate $\mathrm{C} 4$ evolution, although it is not clear whether what was lacking was genetic (a part of the machinery) or environmental (a sufficiently strong selective advantage to drive the transition).

\section{Adaptive evolution of C4 genes}

After duplication, there is evidence that some $\mathrm{C}_{4}$ genes experienced adaptive evolution; however, selection pressures and evolutionary modes have varied. Both maximum likelihood inference and patterns of aggregated amino acid differences indicate that the $\mathrm{C}_{4}$ NADP-ME and PPDK-RP enzyme genes have been under strong selective pressure. Maximum likelihood inference also implies that CA C4 enzymes have experienced positive selection, while aggregated amino acid differences indicate that $\mathrm{C}_{4} \mathrm{PEPC}$ and PPDK genes may also have been under positive selection. The sorghum $\mathrm{C} 4$ genes of PPCK and NADP-MDH enzymes have also accumulated more substitutions than their rice orthologs, though the difference is not statistically significant. Compared to their rice orthologs, PEPC and NADP-MDH C4 genes evolve at a faster rate, providing further evidence of adaptation.

In many cases (NADP-ME, CA, PEPC) evidence from $\mathrm{C}_{4}$ plants supports adaptive evolution of the $\mathrm{C}_{4}$ gene family members only - the non-C4 homologs in $\mathrm{C} 4$ plants show no evidence of adaptive evolution, although the PEPC gene does show evidence in rice ( $\left.\mathrm{C}_{3}\right)$. Further, the strongest evidence of adaptive evolution is in the period when the $\mathrm{C}_{4}$ pathway is thought to have evolved, after the divergence of sorghum and rice, but before the divergence of sorghum and maize.

Adaptive evolution is further supported by patterns of gene expression shown in previous reports. PEPC, PPDK, and CA $\mathrm{C}_{4}$ genes are expressed approximately 20 times more in sorghum mesophyll than bundle-sheath cells, while NADP-ME C4 genes are expressed much more in bundle-sheath than mesophyll cells [35]. The study of Flaveria intermediates shows that PEPC activity is increased approximately 40 times from $\mathrm{C}_{3}$ to full $\mathrm{C}_{4}$ species [65], and the NADP-ME activity is approximately 9 times higher in veins than mesophyll cells [66].

During the process of adaptive evolution, a duplicated gene may gradually acquire a new function (neofunctionalization) or subdivide the functions of its progenitor with the other duplicated copy (subfunctionalization). Laboratory evolution experiments indicated that an evolving new gene can initially acquire increased fitness for a new function without losing its original function [67]. This implies that a neofunctionalization process may begin with an initial subfunctionalization step, an implication that has been supported by theory [68]. It is unclear how long such a step may take. Here, we found that neofunctionalization of $\mathrm{C}_{3}$ genes to function in $\mathrm{C}_{4}$ photosynthesis could take a long time. Previous publications found that both $\mathrm{C}_{4}$ and non- 4 sorghum NADP-MDH genes were expressed in green leaves, though the $\mathrm{C} 4$ gene had higher transcript accumulation $[43,44]$. Together with maximum likelihood analysis involving more genes and different grasses, this finding indicated that $\mathrm{C}_{4}$ and non- 4 sorghum NADP-MDH genes, produced before sorghum-Vetiveria divergence, have experienced subfunctionalization [44]. Sequence alignment here indicates that the sorghum non- 44 gene has been affected by three insertions and one deletion in its amino-terminal coding sequence, suggesting functional innovation. Regardless of whether the process is a division of functions of their progenitor gene, or evolution of a novel function in the non- $\mathrm{C} 4$ gene, co-expression, albeit at divergent levels, of the two genes in green leaves suggests that the process may not yet be finished.

In addition to the possible sheltering effect of a duplicated copy when evolving genetic novelty, alternative splicing may further shelter functional changes. The maize PPDK gene (and probably also its sorghum ortholog) encoding $\mathrm{C}_{4}$ transcripts also encodes cytosolic transcripts. Their rice homolog also has a dual promoter [69], implying that natural selection may have utilized this pre-existing functional duality to evolve $\mathrm{C}_{4}$ function. If $\mathrm{C}_{4}$ transcripts are products of a novel function, and non-C4 transcripts due to the original function, the genes may have retained the original function for millions of years while evolving a novel function. The state of bifunctionality may continue until possible genetic incompatibility, if any, accumulates to a point intolerable to fitness. Maize PPDK may not be the only case of such gene bifunctionality in 
the $\mathrm{C}_{4}$ pathway. As shown above, the sorghum CA gene, Sbo3g029170, seems to have similar bifunctionality, encoding both $\mathrm{C}_{4}$ and non-C4 transcripts. Since its internally repeating structure may have been produced before sorghum-maize divergence, its maize homologs also share this bifunctionality, which may have existed for millions of years. These multiple cases in which alternative splicing may contribute a possible sheltering effect during evolution of new function by $\mathrm{C} 4$ genes imply that it (alternative splicing) may participate in other cases of evolution of genetic novelty.

We found that the sorghum and maize $\mathrm{C}_{4}$ PEPC genes are on a long branch of their gene tree, grouped together with their suspected rice ortholog, showing possible adaptive evolution based on both a high $\mathrm{Ka} / \mathrm{Ks}$ ratio and elevated amino acid substitution. It is intriguing to ask whether possible adaptive evolution in the rice PEPC gene could be a foundation toward a new origin of the $\mathrm{C}_{4}$ pathway, or instead indicates non- $\mathrm{C}_{4}$ functional adaptation. Scrutiny of the rice PEPC sequence revealed only 2 of 12 amino acid substitutions that were previously inferred to be positively selected in $\mathrm{C}_{4}$ genes [42], and, in particular, it lacks the critical fixed mutation $\mathrm{S} 780$ that is shared by $\mathrm{C}_{4}$ PEPC genes in other angiosperms $[41,65]$. This rice gene was classified into the $p p c-B 1$ group [42], found only in the $\mathrm{C}_{3}$ grasses, suggesting that its adaptive evolution is not leading to $\mathrm{C} 4$ photosynthesis, but possibly to other functional novelty.

Adaptive evolution of PEPC may have some valuable implications for the discovery of multiple groups of PEPC genes defined previously [42]. In some $\mathrm{C}_{4}$ grasses there are different groups of genes, such as $p p c-B 2$ and $p p c-C 4$; while another group of genes, $p p c-B 1$, are found in only $\mathrm{C}_{3}$ grasses. These findings show that, in the $\mathrm{C}_{4}$ lineages after their divergence from the $\mathrm{C}_{3}$ lineages but perhaps prior to the evolution of the $\mathrm{C} 4$ pathway itself, further gene duplication(s) may have contributed to the establishment of $\mathrm{C} 4$ photosynthesis.

\section{A novel mode of gene evolution}

The CA enzyme genes display a novel mode of gene evolution and functional adaptation. As shown above, sorghum and maize $\mathrm{C} 4 \mathrm{CA}$ enzymes have one, two or three functional domains, produced through recursive duplications followed by a fusion process involving stop codon mutations in the leading domains. There have been at least four tandem duplication events in sorghum and its ancestral genomes. These tandem duplications started before sorghum-maize divergence, and appear to have continued in the maize lineage. The recurrence of tandem duplications together with the subsequent merger process may have acted as a mode of adaptive evolution. The present CA enzymes are beta-type, comprising a dimer having four zinc ions bound to the structure as active sites. Besides dimers, these enzymes can form tetramers, hexamers or octamers [47], suggesting that the dimer may be a building block. Recruiting extra domains through tandem duplication may contribute to the formation of more complex structures, with more functional binding sites making them work more efficiently to stabilize the balance between $\mathrm{CO}_{2}$ and $\mathrm{HCO}_{3}^{-}$. The expanded gene structure of these sorghum and maize CA genes are unusual, since the cDNAs of Urochloa paniculata and Flaveria bidentis, both $\mathrm{C} 4$ plants, are normal in size [70]. Nonetheless, there is precedent for internal repetition of CA gene structure in red algae, Porphyridium purpureum, resulting in two sets of functional binding sites [71]. This independent evolution of internally repeating structure in CA genes supports our hypothesis that such structure may confer functional advantages.

We found that the sorghum and maize $\mathrm{C}_{4} \mathrm{CA}$ genes share a cTP, which had not been expected since the enzymes were not found to be chloroplastically localized in $\mathrm{C}_{4}$ plants. In $\mathrm{C}_{3}$ plants, the most abundant CA activity is in the chloroplast stroma, while in $\mathrm{C} 4$ plants, the exact location of $\mathrm{CA}$ is less clear [47], but the most abundant CA activity is localized in the cytosol of mesophyll cells [72]. The cTP of sorghum and maize $\mathrm{C}_{4} \mathrm{CA}$ genes is similar to that of the Arabidopsis CA genes, suggesting its existence before monocot-dicot divergence. The preservation of a cTP in $\mathrm{C}_{4}$ genes for tens of millions of years cannot be explained as a mere relic but suggests possible multiple functionality. This inference is at least partially supported by the discovery of divergent functions implemented by two different transcripts produced by the single sorghum $\mathrm{C}_{4} \mathrm{CA}$ gene, Sbo3g029170. As shown above, the expression of the longer transcript is light-inducible, while that of the shorter one is not, indicating that the longer but not the shorter transcript may be involved in the $\mathrm{C} 4$ pathway.

\section{A long transition time from C3 to C4 photosynthesis}

Several evolutionary models have been proposed to explain the formation of the $\mathrm{C} 4$ pathway [73-75]. In summary, seven significant phases are recognized toward successful establishment of $\mathrm{C}_{4}$ photosynthesis: general preconditioning (for example, gene duplication); anatomical preconditioning (for example, close veins); enhancement of bundle-sheath organelles; establishment of photorespiratory $\mathrm{CO}_{2}$ pump and transformation of glycine decarboxylase to bundle-sheath cells; enhancement of PEPC activity; integration; and optimization [6]. Although many biological and anatomical changes are needed, multiple origins in tens of angiosperm families suggest that it is not so difficult to evolve a novel $\mathrm{C} 4$ pathway. However, from an evolutionary viewpoint it is still interesting to ask whether a transition process of gene functional changes and/or enhancement is necessary before the final establishment, and how long such a transition might take. There has been a long time-lag between the initial decrease in $\mathrm{CO}_{2}$ concentration and the appearance of $\mathrm{C}_{4}$ plants. The initial decrease in $\mathrm{CO}_{2}$ concentration started at least 100 mya [6], while molecular clock analyses suggest that the earliest $\mathrm{C}_{4}$ 
plants (grasses) appeared about 24 to 35 mya [28,29] One proposed explanation for the time-lag was the lack of a sufficient reservoir of duplicated and neofunctionalized $\mathrm{C}_{3}$ genes to support $\mathrm{C} 4$ evolution [14]. Here, we found that the genes of key enzymes, such as PEPC and NADP-ME, were among the duplicated copies produced by the WGD approximately 70 mya $[19,20]$. Once again we note, however, that availability of the pan-cereal duplicated copies was not by itself sufficient to initiate $\mathrm{C}_{4}$ evolution, since some were lost from the common cereal ancestor and then, after divergence from rice, had to reduplicate in the sorghum-maize ancestor before $\mathrm{C} 4$ evolution could occur.

\section{Differential duplicability of C4 genes and their non-C4 isoforms}

The above characterization of gene duplication shows differential duplicability of $\mathrm{C}_{4}$ genes and their isoforms in grasses. Evidence from yeast indicates that gene redundancy tends to be preserved among some of the central proteins in the cellular interaction network [76]. Tens of plant genes were suggested to be duplication-resistant, and undergo convergent restoration to singleton status following several independent genome duplications [25]. The differential duplicability could be explained by gene dosage effects, organismal complexity, protein interaction centrality and protein domain preference [24-26,76]. Here, we have shown that some gene families, including PEPC, PPCK, CA, and NADP-ME genes, have been expanded by gene duplication, but not others such as PPDK genes. The families expanded by gene duplication tend to be multiply functional, such as PEPC and NADP-ME [14]. Different PEPC gene isoforms take on specific roles, including the regulation of ion balance, the production of amino-group acceptor molecules in symbiotic nitrogen fixation, and the initial fixation of $\mathrm{C}$ in $\mathrm{C} 4$ photosynthesis and Crassulacean acid metabolism [77]. NADP-ME catalyzes the oxidative breakdown of malate to form $\mathrm{CO}_{2}$ and pyruvate in the $\mathrm{C} 4$ pathway. Its non-C4 functions include the provision of carbon skeletons for ammonia assimilation [78] and reductant for wound-induced production of lignin and flavonoids $[79,80]$. CA genes are also prone to duplication, which may enhance their ability to form more complex structures, as discussed above. Though further duplication is not required when a former $\mathrm{C}_{3}$ gene is finally co-opted for $\mathrm{C}_{4}$ roles [14], we found that the sorghum NADP-MDH $\mathrm{C}_{4}$ gene did experience a tandem duplication event, with only one duplicated copy preserving the $\mathrm{C}_{4}$ function through possible subfunctionalization [44]. This implies that the sorghum NADP-MDH C4 gene itself may be duplication-resistant.

\section{C4 pathway and codon usage bias}

GC content elevation has resulted in codon usage bias [37], which has been hypothesized by some to have contributed to $\mathrm{C} 4$ adaptive evolution [30]. As shown above, though the grass $\mathrm{C}_{4}$ genes and their isoforms always have a higher GC content than their Arabidopsis counterparts, there is often a non-C4 grass gene having higher GC content than the $\mathrm{C}_{4}$ one(s).
Thus, there is no clear evidence supporting co-variation between codon usage bias and $\mathrm{C} 4$ gene evolution. Base composition variation in grass genes has been a hot topic involving transcription, translation, modification and mutational bias [81-83].

\section{Potential contribution to engineering new C4 plants}

A comprehensive characterization of the $\mathrm{C} 4$ pathway will help not only to understand how $\mathrm{C} 4$ photosynthesis evolves, but also may benefit crop improvement efforts. Of singular relevance are efforts to transform $\mathrm{C}_{3}$ plants into $\mathrm{C}_{4}$ plants. To perform such a transformation, one strategy is to incorporate the $\mathrm{C}_{4}$ pathway into $\mathrm{C}_{3}$ plants through recombinant DNA technology [84]. The strategy succeeds in transferring $\mathrm{C}_{4}$ genes into $\mathrm{C}_{3}$ plants and yielding high levels of $\mathrm{C}_{4}$ enzymes in desired locations $[85,86]$. It is of great interest to transform rice, a staple food for more than half of the world's population, to perform $\mathrm{C}_{4}$ function, as reviewed in a recent publication [31]. However, combined overproduction of C4 enzymes (PEPC, PPDK, NADP-ME, and NADP-MDH) resulted in only slightly higher levels of $\mathrm{CO} 2$ assimilation than in wild-type rice [87]. This might indicate that not all components needed for $\mathrm{C} 4$ photosynthesis are known. There must be some transporters involved and there might also be some unknown regulatory factors. Knowledge of the complete sorghum genome might help to identify such components. As also shown above, though often not statistically significant, the sorghum and maize $\mathrm{C}_{4}$ genes appear to have been under adaptive evolution in different modes and levels, and show different duplicability. These findings may provide clues toward a successful transformation to $\mathrm{C} 4$ photosynthesis. Alternatively, perhaps adaptations such as we have suggested in the PEPC gene in $\mathrm{C}_{3}$ lineages have mitigated the perceived weaknesses of $\mathrm{C}_{3}$ photosynthesis.

Subtle differences in the $\mathrm{C}_{4}$ pathways used in different grasses are worthy of further investigation as well. For example, if our hypothesis is correct that internally repeating structure in CA genes may confer functional advantages, then engineering of the maize trimer into sorghum (for example) may be advantageous. Likewise, exploration of still more recent polyploids such as sugarcane might yield even more complex CA alleles. Tandem duplication of $\mathrm{C}_{4} \mathrm{NADP}-\mathrm{MDH}$ following the sorghum-maize divergence does not appear to have been essential to $\mathrm{C} 4$ evolution; indeed, one of the tandem genes appears to have lost $\mathrm{C} 4$ specificity. However, careful scrutiny of the physiological consequences of this change might suggest benefits that could be transferred to other crops.

\section{Conclusions Gene duplication and C4 pathway evolution}

Both WGD and single-gene duplication have contributed to $\mathrm{C} 4$ pathway evolution in sorghum and maize. Some 44 genes (PEPC, PPCK, and NADP-ME C4 genes) were recruited from 
duplicates produced by WGD. Sorghum NADP-MDH, NADPME and PPDK-RP C4 genes were affected by tandem duplication, with only one of the resulting copies involved in the $\mathrm{C}_{4}$ pathway. $\mathrm{C} 4$ genes show divergent duplicability. PEPC, NADP-ME, PPCK, and CA gene families were expanded by recursive duplication events, showing a duplication-philic nature, whereas NADP-MDH and PPDK are likely duplication-phobic. Further supporting evidence is that only one copy of NADP-MDH $\mathrm{C}_{4}$ gene duplicates preserves the $\mathrm{C}_{4}$ function.

\section{Adaptive evolution divergent in mode and level}

We found evidence of adaptive evolution of most $\mathrm{C}_{4}$ genes studied. However, the mode and level of adaptation is divergent among $\mathrm{C}_{4}$ genes. Adaptive evolution is achieved though rapid mutations in DNA sequences, aggregated amino acid substitutions, and/or considerable increases of expression levels in specific cells. Besides gene redundancy, we found that alternative splicing may have also sheltered the evolution of new function. Our analysis supports previous findings that maximum likelihood inference may be too conservative to find adaptive evolution. We found no evidence of co-variation between codon usage bias and $\mathrm{C}_{4}$ pathway development.

\section{Special evolutionary mode of grass CA genes}

Grass CA genes have evolved in a specific pattern featuring recursive tandem duplication and neighboring gene fusion, which produced distinct isoforms having one to three functional units. Two sorghum $\mathrm{C}_{4} \mathrm{CA}$ genes have one and two functional units, while two characterized maize $\mathrm{C}_{4} \mathrm{CA}$ genes have two and three functional units, respectively. The elongation of these genes by recruiting extra domains may contribute to the formation of more complex protein structures, as often observed in plants.

\section{A long transition time from C3 to C4 photosynthesis} The hypothesis that a reservoir of duplicated genes in ancestral $\mathrm{C}_{3}$ plants was a prerequisite for $\mathrm{C}_{4}$ pathway development is only partially supported by present findings that some $\mathrm{C}_{4}$ genes were recruited from the duplicates. Availability of the pan-cereal duplicated copies was not sufficient to initiate $\mathrm{C}_{4}$ evolution, since some were lost from the common cereal ancestor, then had to reduplicate in the sorghum-maize ancestor before $\mathrm{C}_{4}$ evolution could occur. However, $\mathrm{C}_{4}$ gene isoforms show quite divergent duplicability, and there has been quite a long time-lag between the gene duplication events and the appearance of $\mathrm{C}_{4}$ grasses. These findings suggest a long transition process, including different modes of functional innovation, before the eventual establishment of C4 photosynthesis.

\section{Materials and methods}

Known C4 enzyme genes and their non-C4 isoforms in sorghum, maize and Arabidopsis (Table 1) were downloaded from NCBI CoreNucleotide database [88]. Searching these known genes against sorghum [89] and rice [90] gene models by running BLAST [91] (E-value $<1 \times 10^{-5}$ ), we identified other enzyme genes in these organisms. By characterizing sequence similarity and constructing gene trees, possible $\mathrm{C} 4$ genes were determined. The enzymes revealed here were linked to expression data reported previously [35] by comparing cDNA segments to gene sequences using BLAST.

\section{Gene colinearity inference}

The potential gene homology information defined by running BLAST was used as the input for MCscan [92] to find homologous gene pairs in colinearity. The built-in scoring scheme for MCscan is $\min \left(-\log _{10} E \_\right.$value, 50) for every matching gene pair and -1 for each $10 \mathrm{~kb}$ distance between anchors, and blocks that had scores $>300$ were kept. The resulting syntenic chains were evaluated using a procedure by ColinearScan [17] and an E-value $<1 \times 10^{-10}$ was used as a significance cutoff.

\section{Gene phylogeny construction}

We constructed phylogenetic trees using several approaches, including the neighbor-joining, maximum likelihood, minimal evolution, and maximum parsimony methods, implemented in NADP-MEGA [93], PHYML [94], and PHYLIP [95], on both DNA and protein sequences. While running PHYML, parameters were set as adopted previously [42]. Bootstrap tests were performed with 100 repeats to produce percentage values, showing the stability of their topology. The trees mostly agree with one another. When there is inconsistency, the tree most strongly supported by bootstrap values was adopted for the subsequent adaptive evolution inference. For example, the trees of CA functional units were inconsistent among methods, and the best-supported neighbor-joining tree produced by protein sequences was adopted for further analysis.

\section{Maximum likelihood inference of adaptive evolution}

The tree constructed for the group of $\mathrm{C}_{4}$ enzyme genes and their non-C4 isoforms was used to perform further maximum likelihood analysis using the Codeml program in PAML [96]. To detect whether a specific $\mathrm{C}_{4}$ gene had been positively selected, we compared two types of competing models: a freeratio model and a ratio-restriction model [97]. The free-ratio model assumes an independent $\mathrm{Ka} / \mathrm{Ks}$ ratio for each branch, whereas the latter forces the $\mathrm{Ka} / \mathrm{Ks}$ ratio to be 1 on the specific branch to be tested for positive selection, and for the other branches assumes independent ratios. Each model will produce a likelihood, and the twofold difference between them follows a Chi-squared distribution with 1 degree of freedom.

\section{Aggregated amino acid substitution analysis}

We adopted a comparative genomic approach initially proposed by Wagner [98] to detect genes potentially under positive selection. The Wagner approach inferred positive selection pressure by detecting possible aggregation of amino acid replacement. Here, we inferred possible amino acid replacements by comparing the homologous enzyme gene 
pair containing a $\mathrm{C}_{4}$ gene and non- $\mathrm{C}_{4}$ gene (often a rice gene) against the aligned outgroup sequence. A replacement site is identified in the $\mathrm{C}_{4}$ sequence that differs from the corresponding sites in both the homologous sequence and the outgroup sequence, which are identical. We found the number of all replacements, $\mathrm{m}$, grouping the $\mathrm{C}_{4}$ and non- $\mathrm{C} 4$ protein sequences. If the occurrences of these replacement sites are assumed to be Poisson distributed with a parameter $\lambda$, we may evaluate the chance of observing a specific number of consecutive replacement sites along a sequence. For simplicity in description, for each sequence we first defined a replacement position array, $x=x_{0}, x_{1}, x_{2}, \ldots, x_{t}, x_{t+1}$, composed by all the positions $x_{i}(1 \leq \mathrm{i} \leq t)$ of replacement sites and two ends of the sequence, that is, $x_{0}=0$ and $x_{t+1}=n-1$, where $n$ is the length of the alignment after purging gaps. Then we defined the replacement distance array, $d=\left(d_{1}, \ldots d_{t+1}\right)$, where $d_{1}=x_{i}-x_{i-1}(1 \leq \mathrm{i} \leq t+1)$. The distance between two replacement sites $d_{i, k}=x_{i+k-1}-x_{i}$, where $k$ is the number of the consecutive replacement sites in the corresponding sequence segment, follows a Pearson type III distribution following a probability density $\lambda(\lambda z)^{k-2} e^{-\lambda z} / \Gamma(k-1)$ [99], where $\Gamma(k-1)=$ $(k-1)$ !. We can estimate the Poisson parameter $\lambda$ with $\mathrm{m} /$ (2n). Supposing there are $t_{i}$ replacement sites along the $i$-th sequence, obviously, we get $\sum_{i=1}^{2} t_{i}=m$. Therefore, we could estimate the probability $P\left(d_{i, k}\right)$ that $k$ consecutive replacements in a distance between two replacement sites is smaller than the observed $d_{i, k}$ by the following integration:

$$
P\left(d_{i, k}\right)=\frac{\lambda}{\Gamma(k-1)} \int_{0}^{d_{i, k}}(\lambda z)^{k-2} e^{-\lambda z} d z
$$

We evaluated the occurrence probability of observed distance between any two replacement sites, and the smallest probability was used to locate a region with the most aggregated replacements, which was taken to be significant after a Bonferroni correction by considering the number of all combinations of replacement sites $\left(\left(\begin{array}{c}t+2 \\ 2\end{array}\right)\right)$. The occurrence probability was calculated using $\mathrm{R}$ [100]. If between two replacement sites there were gaps in the aligned sequences, they were omitted to check for possible selection. We composed Perl scripts to implement the described approach.

\section{Maize homolog characterization}

Maize BACs are from the MaizeSequence database [101]. The maize genes were searched against the BAC sequences to reveal their chromosomal locations, local DNA structures, and so on.

\section{Chloroplastic transit peptide inferrence}

ChloroP1.1 [102] was used to predict the presence of cTPs in the enzyme protein sequences and the location of potential cTP cleavage sites

\section{Dotplotting}

Dotplots between CA protein sequences were produced by running the public program DOTTER [103]. The Dotplots were produced by matched strings from two protein sequences in comparison. The expected score per residue of the matched strings was set to be 40 .

\section{Abbreviations}

BAC: bacterial artificial chromosome; CA: carboxylating anhydrase; cTP: chloroplast transit peptide; $\mathrm{MDH}$ : malate dehydrogenase; mya: million years ago; NADP-ME: NADPmalic enzyme; PEPC: phosphoenolpyruvate carboxylase; PPCK: PEPC kinase; PPDK: pyruvate orthophosphate dikinase; PPDK-RP: PPDK regulatory protein; WGD: wholegenome duplication.

\section{Authors' contributions}

XW designed and organized the present work. UG, PW and XW curated gene models. UG, HT, JEB and AHP contributed to this work through critical discussion. XW and AHP wrote the paper.

\section{Additional files}

The following additional data are available with the online version of this paper: Tables $\mathrm{S} 1$ to $\mathrm{S} 4$ (Additional data file 1); a full tree of PEPC genes (Additional data file 2); cTPs detected by ChloroP (Additional data file 3); CA gene sequences and their functional units (Additional data file 4).

\section{Acknowledgements}

We appreciate financial support from the US National Science Foundation (MCB-0450260 to AHP). We thank Lifeng Lin for artwork.

\section{References}

I. Hatch MD, Slack CR: Photosynthesis by sugar-cane leaves. A new carboxylation reaction and the pathway of sugar formation. Biochem J 1966, I0I(I): I03-III.

2. Seemann JR, Sharkey TD, Wang J, Osmond CB: Environmental Effects on Photosynthesis, Nitrogen-Use Efficiency, and Metabolite Pools in Leaves of Sun and Shade Plants. Plant physiology 1987, 84(3):796-802.

3. Hattersley PG: The distribution of $\mathbf{C 3}$ and $\mathbf{C 4}$ grasses in Australia in relation to climate. Oecologia 1983, 57: I I3-128.

4. Ehleringer JR, Bjorkman O: A Comparison of Photosynthetic Characteristics of Encelia Species Possessing Glabrous and Pubescent Leaves. Plant physiology 1978, 62(2): 185-190.

5. Cerling TE, Harris JM, MacFadden BJ, Leasey MG, Quade J, Eisenmann $\mathrm{V}$, Ehleringer JR: Global vegetation change through the Miocene/Pliocene boundary. Nature 1997, 389:।53-I58.

6. Sage RF: The evolution of $\mathbf{C} \mathbf{4}$ photosynthesis. New Phytologist 2004, I 6 I:341-370.

7. Mulhaidat R, Sage RF, Dengler NG: Diversity of kranz anatomy 
and biochemistry in C4 eudicots. American Journal of Botany 2007, 94(3):20.

8. Giussani LM, Cota-Sanchez JH, Zuloaga FO, Kellogg EA: A molecular phylogeny of the grass subfamily Panicoideae (Poaceae) shows multiple origins of C4 photosynthesis. American Journal of Botany 200I, 88(I I): I993-20I2.

9. Pyankov VI, Artyusheva EG, Edwards GE, Black CC Jr, Soltis PS: Phylogenetic analysis of tribe Salsoleae (Chenopodiaceae) based on ribosomal ITS sequences: implications for the evolution of photosynthesis types. Am J Bot 200I, 88(7): I I89-I I98.

10. Sheen J: C4 Gene Expression. Annu Rev Plant Physiol Plant Mol Biol 1999, 50:187-217.

II. Burnell JN, Chastain CJ: Cloning and expression of maize-leaf pyruvate, $\mathrm{Pi}$ dikinase regulatory protein gene. Biochem Biophys Res Commun 2006, 345(2):675-680.

12. Kawamura T, Shigesada K, Toh H, Okumura S, Yanagisawa S, Izui K: Molecular evolution of phosphoenolpyruvate carboxylase for C4 photosynthesis in maize: comparison of its cDNA sequence with a newly isolated cDNA encoding an isozyme involved in the anaplerotic function. J Biochem 1992, I I 2(I): 147-154

13. Poetsch W, Hermans J, Westhoff P: Multiple cDNAs of phosphoenolpyruvate carboxylase in the $\mathrm{C} 4$ dicot Flaveria trinervia. FEBS Letters |99|, 292:| $33-136$.

14. Monson RK: Gene duplication, neofunctionalization, and the evolution of C4 photosynthesis. International Journal of Plant Science 2003, 164(6920):S43-S54.

15. Bowers JE, Chapman BA, Rong J, Paterson AH: Unravelling angiosperm genome evolution by phylogenetic analysis of chromosomal duplication events. Nature 2003, 422(6930):433-438.

16. Yu J, Wang J, Lin W, Li S, Li H, Zhou J, Ni P, Dong W, Hu S, Zeng C, Zhang J, Zhang Y, Li R, Xu Z, Li S, Li X, Zheng H, Cong L, Lin L, Yin J, Geng J, Li G, Shi J, Liu J, Lv H, Li J, Wang J, Deng Y, Ran L, Shi X, et al.: The Genomes of Oryza sativa: A History of Duplications. PLoS Biology 2005, 3(2):e38.

17. Wang X, Shi X, Li Z, Zhu Q, Kong L, Tang W, Ge S, Luo J: Statistical inference of chromosomal homology based on gene colinearity and applications to Arabidopsis and rice. $B M C$ bioinformatics 2006, 7(I):447.

18. Blanc G, Wolfe $\mathrm{KH}$ : Widespread paleopolyploidy in model plant species inferred from age distributions of duplicate genes. The Plant cell 2004, 16(7):1667-1678.

19. Paterson AH, Bowers JE, Chapman BA: Ancient polyploidization predating divergence of the cereals, and its consequences for comparative genomics. Proc Natl Acad Sci USA 2004, I $01(26): 9903-9908$.

20. Wang X, Shi X, Hao B, Ge S, Luo J: Duplication and DNA segmental loss in the rice genome: implications for diploidization. New Phytologist 2005, I 65(3):937-946.

21. Paterson AH, Bowers JE, Bruggmann R, Dubchak I, Grimwood J, Gundlach H, Haberer G, Hellsten U, Mitros T, Poliakov A, Schmutz J, Spannagl M, Tang H, Wang X, Wicker T, Bharti AK, Chapman J, Feltus FA, Gowik U, Grigoriev IV, Lyons E, Maher CA, Martis M, Narechania A, Otillar RP, Penning BW, Salamov AA, Wang Y, Zhang L, Carpita NC, et al:: The Sorghum bicolor genome and the diversification of grasses. Nature 2009, 457(7229):55I-556.

22. Lynch $M$, Conery JS: The evolutionary demography of duplicate genes. I Struct Funct Genomics 2003, 3( I-4):35-44.

23. He X, Zhang J: Gene complexity and gene duplicability. Curr Biol 2005, I 5(I I): 1016-102I.

24. Liang $\mathrm{H}, \mathrm{Li}$ WH: Gene essentiality, gene duplicability and protein connectivity in human and mouse. Trends Genet 2007, 23(8):375-378.

25. Paterson AH, Chapman BA, Kissinger JC, Bowers JE, Feltus FA, Estill JC: Many gene and domain families have convergent fates following independent whole-genome duplication events in Arabidopsis, Oryza, Saccharomyces and Tetraodon. Trends Genet 2006, 22(II):597-602.

26. Papp $B, P a l C$, Hurst LD: Dosage sensitivity and the evolution of gene families in yeast. Nature 2003, 424(6945): $194-197$.

27. Nielsen R, Bustamante C, Clark AG, Glanowski S, Sackton TB, Hubisz MJ, Fledel-Alon A, Tanenbaum DM, Civello D, White TJ, J JS, Adams MD, Cargill M: A scan for positively selected genes in the genomes of humans and chimpanzees. PLOS biology 2005, 3(6): 170 .

28. Vicentini A, Barber JC, Aliscioni SS, Ciussani LM, Kellogg EA: The age of the grasses and clusters of origins of $\mathrm{C} 4$ photosynthesis.
Global Change Biology 2008, 14:15.

29. Christin PA, Besnard G, Samaritani E, Duvall MR, Hodkinson TR, Savolainen V, Salamin N: Oligocene CO2 decline promoted C4 photosynthesis in grasses. Curr Biol 2008, I 8(I):37-43.

30. Shenton M, Fontaine V, Hartwell J, Marsh JT, Jenkins GI, Nimmo HG: Distinct patterns of control and expression amongst members of the PEP carboxylase kinase gene family in C4 plants. Plant J 2006, 48(I):45-53.

31. Sheehy JE, Mitchell PL, Hardy B: Charting New Pathways To C4 Rice. Los Banos (philippines): World Scientific Publishing Company; 2008

32. Sanchez R, Cejudo FJ: Identification and expression analysis of a gene encoding a bacterial-type phosphoenolpyruvate carboxylase from Arabidopsis and rice. Plant physiology 2003, I32(2):949-957.

33. Cretin C, Keryer E, Tagu D, Lepiniec L, Vidal J, Gadal P: Complete cDNA sequence of sorghum phosphoenolpyruvate carboxylase involved in C4 photosynthesis. Nucleic acids research 1990, 18(3):658.

34. Cretin C, Santi S, Keryer E, Lepiniec L, Tagu D, Vidal J, Gadal P: The phosphoenolpyruvate carboxylase gene family of Sorghum: promoter structures, amino acid sequences and expression of genes. Gene 199|, 99(I):87-94.

35. Wyrich R, Dressen U, Brockmann S, Streubel M, Chang C, Qiang D, Paterson AH, Westhoff $P$ : The molecular basis of $C 4$ photosynthesis in sorghum: isolation, characterization and RFLP mapping of mesophyll- and bundle-sheath-specific cDNAs obtained by differential screening. Plant molecular biology 1998, 37(2):319-335.

36. Song R, Llaca V, Messing J: Mosaic organization of orthologous sequences in grass genomes. Genome Res 2002, I 2(10): I549-1555.

37. Carels N, Bernardi G: Two classes of genes in plants. Genetics 2000, 154(4): $1819-1825$.

38. Lepiniec L, Keryer E, Philippe H, Gadal P, Cretin C: Sorghum phosphoenolpyruvate carboxylase gene family: structure, function and molecular evolution. Plant molecular biology 1993 , 2 I (3):487-502.

39. Besnard G, Offmann B, Robert C, Rouch C, Cadet F: Assessment of the $\mathbf{C}(4)$ phosphoenolpyruvate carboxylase gene diversity in grasses (Poaceae). Theor Appl Genet 2002, 105(2-3):404-4I2.

40. Roth C, Liberles DA: A systematic search for positive selection in higher plants (Embryophytes). BMC plant biology 2006, 6: 12 .

41. Westhoff P, Gowik U: Evolution of c4 phosphoenolpyruvate carboxylase. Genes and proteins: a case study with the genus Flaveria. Ann Bot (Lond) 2004, 93(I): I 3-23.

42. Christin PA, Salamin N, Savolainen V, Duvall MR, Besnard G: C4 Photosynthesis evolved in grasses via parallel adaptive genetic changes. Curr Biol 2007, I7(14): I24I-1247.

43. Luchetta P, Cretin C, Gadal P: Organization and expression of the two homologous genes encoding the NADP-malate dehydrogenase in Sorghum vulgare leaves. Mol Gen Genet 1991, 228(3):473-481.

44. Rondeau P, Rouch C, Besnard G: NADP-malate dehydrogenase gene evolution in Andropogoneae (Poaceae): gene duplication followed by sub-functionalization. Ann Bot (Lond) 2005, 96(7): $1307-13 \mid 4$

45. Sheen J: Molecular mechanisms underlying the differential expression of maize pyruvate, orthophosphate dikinase genes. The Plant cell 1991, 3(3):225-245.

46. Glackin CA, Grula JW: Organ-specific transcripts of different size and abundance derive from the same pyruvate, orthophosphate dikinase gene in maize. Proceedings of the National Academy of Sciences of the United States of America 1990, 87(8):3004-3008.

47. Tiwari $A$, Kumar $P$, Singh $S$, Ansari S: Carbonic anhydrase in relation to higher plants. Photosynthetica 2005, 43(I): I-II.

48. Wolfe $\mathrm{KH}$, $\mathrm{Li}$ WH: Molecular evolution meets the genomics revolution. Nature genetics 2003, 33(Suppl):255-265.

49. Haldane JBS: The causes of evolution. Ithaca: Cornell University Press; 1932.

50. Ohno S: Sex chromosomes and sex-linked genes. Berlin: Springler-Verlag; 1967.

5I. Ohno S: Evolution by Gene Duplication. Berlin-Heidelberg_New York: Springer-Verlag; 1970

52. Steinke D, Hoegg S, Brinkmann H, Meyer A: Three rounds (IR/2R/ $3 R$ ) of genome duplications and the evolution of the glycolytic pathway in vertebrates. BMC Biol 2006, 4:16. 
53. Meyer A, Peer Y Van de: From 2R to 3R: evidence for a fish-specific genome duplication (FSGD). Bioessays 2005, 27(9):937-945.

54. Soltis PS: Ancient and recent polyploidy in angiosperms. The New phytologist 2005, I66(I):5-8.

55. Jaillon O, Aury JM, Noel B, Policriti A, Clepet C, Casagrande A, Choisne N, Aubourg S, Vitulo N, Jubin C, Vezzi A, Legeai F, Hugueney P, Dasilva C, Horner D, Mica E, Jublot D, Poulain J, Bruyere C, Billault A, Segurens B, Gouyvenoux M, Ugarte E, Cattonaro F, Anthouard V, Vico V, Del Fabbro C, Alaux M, Di Gaspero G, Dumas V, et al.: The grapevine genome sequence suggests ancestral hexaploidization in major angiosperm phyla. Nature 2007, 449(7 I 6I):463-467.

56. Tang H, Bowers JE, Wang X, Ming R, Alam M, Paterson AH: Synteny and collinearity in plant genomes. Science 2008, 320(5875):486-488.

57. Chapman BA, Bowers JE, Feltus FA, Paterson AH: Buffering crucial functions by paleologous duplicated genes may impart cyclicality to angiosperm genome duplication. Proceedings of the National Academy of Sciences of the United States of America 2006, I 03:2730-2735

58. Maere S, De Bodt S, Raes J, Casneuf T, Van Montagu M, Kuiper M, Peer $Y$ Van de: Modeling gene and genome duplications in eukaryotes. Proceedings of the National Academy of Sciences of the United States of America 2005, I 02( I 5):5454-5459.

59. Blanc $\mathrm{G}$, Wolfe $\mathrm{KH}$ : Functional divergence of duplicated genes formed by polyploidy during Arabidopsis evolution. The Plant cell 2004, I6(7):1679-1691.

60. Seoighe C, Gehring C: Genome duplication led to highlyselective expansion of the Arabidopsis thaliana proteome. Trends Genet 2004, 20( I 0):46I-464.

61. Freeling M, Thomas BC: Gene-balanced duplications, like tetraploidy, provide predictable drive to increase morphological complexity. Genome research 2006, I 6(7):805-8|4

62. De Bodt S, Maere S, Peer Y Van de: Genome duplication and the origin of angiosperms. Trends in ecology \& evolution (Personal edition) 2005, 20( I I):59I-597.

63. Salse J, Bolot S, Throude M, Jouffe V, Piegu B, Quraishi UM, Calcagno $T$, Cooke R, Delseny M, Feuillet C: Identification and characterization of shared duplications between rice and wheat provide new insight into grass genome evolution. The Plant cell 2008, 20: I |-24.

64. Shantz HL: The place of grasslands in the earth's cover of vegetation. Ecology 1954, 35:|43-145.

65. Svensson P, Blasing OE, Westhoff P: Evolution of C4 phosphoenolpyruvate carboxylase. Arch Biochem Biophys 2003, 4|4(2): | $80-188$

66. Hibberd JM, Quick WP: Characteristics of C4 photosynthesis in stems and petioles of C3 flowering plants. Nature 2002, 4I5(6870):45I-454.

67. Aharoni A, Gaidukov L, Khersonsky O, McQ GS, Roodveldt C, Tawfik DS: The 'evolvability' of promiscuous protein functions. Nature genetics 2005, 37(I):73-76.

68. He XL, Zhang JZ: Rapid subfunctionalization accompanied by prolonged and substantial neofunctionalization in duplicate gene evolution. Genetics 2005, 169(2): I I57-I I64.

69. Matsuoka M: The gene for pyruvate, orthophosphate dikinase in C4 plants: structure, regulation and evolution. Plant \& cell physiology 1995, 36(6):937-943.

70. Moroney JV, Bartlett SG, Samuelsson G: Carbonic anhydrases in plants and algae. Plant Cell and Environment 200I, 24:I3

7I. Mitsuhashi S, Mizushima T, Yamashita E, Yamamoto M, Kumasaka T, Moriyama H, Ueki T, Miyachi S, Tsukihara T: X-ray structure of beta-carbonic anhydrase from the red alga, Porphyridium purpureum, reveals a novel catalytic site for $\mathbf{C O}(2)$ hydration. The Journal of biological chemistry 2000, 275(8):552 I-5526.

72. Ku MS, Kano-Murakami Y, Matsuoka M: Evolution and expression of C4 photosynthesis genes. Plant physiology 1996, I I I (4):949-957.

73. Edwards GE, Ku MSB: Biochemistry of C3-C4 intermediates. In The Biochemistry of Plants Volume 10. Edited by: Hatch MD, Boardman NK. London: Academic Press; 1987:275-325.

74. Brown RH, Hattersley PW: Leaf Anatomy of C(3)-C(4) Species as Related to Evolution of C(4) Photosynthesis. Plant physiology 1989, $91: 1543-1550$.

75. Rawsthorne S: Towards an understanding of C3-C4 photosynthesis. Essays Biochem 1992, 27:135-146.

76. Kafri R, Dahan O, Levy J, Pilpel Y: Preferential protection of pro- tein interaction network hubs in yeast: evolved functionality of genetic redundancy. Proceedings of the National Academy of Sciences of the United States of America 2008, I 05(4): I 243-I248.

77. Gehring $\mathrm{HH}$, Heute V, Kluge M: Toward a better knowledge of the molecular evolution of phosphoenolpyruvate carboxylase by comparison of partial cDNA sequences. Journal of molecular evolution 1998, 46:107-II4.

78. Chopra J, Kaur N, Gupta AK: A comparative developmental pattern of enzymes of carbon metabolism and pentose phosphate pathway in mungbean and lentil nodules. Acta Physio Plant 2002, 24:67-72.

79. Casati P, Drincovich MF, Edwards GE, Andreo CS: Malate metabolism by NADP-malic enzyme in plant defense. Photosynth Res 1999, 61:99-105.

80. Maurino VG, Saigo M, Andreo CS, Drincovich MF: Non-photosynthetic 'malic enzyme' from maize: a constituvely expressed enzyme that responds to plant defence inducers. Plant molecular biology 200I, 45(4):409-420.

8I. Wong GK, Wang J, Tao L, Tan J, Zhang J, Passey DA, Yu J: Compositional gradients in Gramineae genes. Genome research 2002 , I 2(6):85|-856.

82. Wang HC, Singer GA, Hickey DA: Mutational bias affects protein evolution in flowering plants. Mol Biol Evol 2004, 2 I ( I):90-96.

83. Shi X, Wang X, Li Z, Zhu Q, Yang J, Ge S, Luo J: Evidence that natural selection is the primary cause of the $G C$ content variation in rice genes. Journal of Integrative Plant Biology 2007.

84. Miyao M: Molecular evolution and genetic engineering of C4 photosynthetic enzymes. J Exp Bot 2003, 54(38I):I79-I89.

85. Ku MS, Agarie S, Nomura M, Fukayama H, Tsuchida H, Ono K, Hirose S, Toki S, Miyao M, Matsuoka M: High-level expression of maize phosphoenolpyruvate carboxylase in transgenic rice plants. Nat Biotechnol 1999, I 7( I):76-80.

86. Fukayama $H$, Tsuchida $H$, Agarie $S$, Nomura M, Onodera $H$, Ono $K$, Lee BH, Hirose S, Toki S, Ku MS, Makino A, Matsuoka M, Miyao M: Significant accumulation of $\mathbf{C}(4)$-specific pyruvate, orthophosphate dikinase in a C(3) plant, rice. Plant physiology 2001 , I 27(3): | | 36- | |46.

87. Taniguchi $\mathrm{Y}$, Ohkawa H, Masumoto C, Fukuda T, Tamai T, Lee K, Sudoh S, Tsuchida H, Sasaki H, Fukayama H, Miyao M: Overproduction of $\mathrm{C4}$ photosynthetic enzymes in transgenic rice plants: an approach to introduce the C4-like photosynthetic pathway into rice. J Exp Bot 2008, 59(7): $1799-1809$.

88. NCBI CoreNucleotide database [http://www.ncbi.nlm.nih.gov/]

89. Joint Genome Institute [http://www.jgi.doe.gov/]

90. Rice annotation project 2 [http://rgp.dna.affrc.go.jp/E/index.html/ ]

9I. Altschul SF, Gish W, Miller W, Myers EW, Lipman DJ: Basic loca alignment search tool. Journal of molecular biology 1990, 2 I5:403-410

92. Tang HB, Wang XY, Bowers JE, Ming R, Alam M, Paterson AH: Unreveling ancient hexaploidy throught multiply-aligned angiosperm gene maps. Genome research 2008.

93. Tamura K, Dudley J, Nei M, Kumar S: MEGA4: Molecular Evolutionary Genetics Analysis (MEGA) software version 4.0. Mol Biol Evol 2007, 24(8): I596-I599.

94. Guindon S, Lethiec F, Duroux P, Gascuel O: PHYML Online--a web server for fast maximum likelihood-based phylogenetic inference. Nucleic acids research 2005:W557-559.

95. Felsenstein J: Phylogenies From Restriction Sites - a Maximum-Likelihood Approach. Evolution 1992, 46(I): I59-I73.

96. Yang Z, Nielsen R: Synonymous and nonsynonymous rate variation in nuclear genes of mammals. Journal of molecular evolution 1998, 46(4):409-418.

97. Yang Z: Likelihood ratio tests for detecting positive selection and application to primate lysozyme evolution. Mol Biol Evol 1998, 15:568-573.

98. Wagner A: Rapid detection of positive selection in genes and genomes through variation clusters. Genetics 2007, I76(4):245 I-2463.

99. Wagner A: A computational genomics approach to the identification of gene networks. Nucleic acids research 1997, 25( I 8):3594-3604.

100. R language [http://www.r-project.org/]

I0I. MaizeSequence [http://www.maizesequence.org/]

102. Emanuelsson $\mathrm{O}$, Nielsen $\mathrm{H}$, von Heijne G: ChloroP, a neural network-based method for predicting chloroplast transit peptides and their cleavage sites. Protein Sci 1999, 8(5):978-984. 
103. Sonnhammer ELL, Durbin R: A dot-matrix program with dynamic threshold control suitable for genomic DNA and protein sequence analysis. Gene 1995, 167:1-10. 